\title{
Carbonylated indoles from Pd"-catalyzed intermolecular reactions of indolyl cores
}

\author{
Jean Le Bras \\ Jacques Muzart* \\ Institut de Chimie Moléculaire de Reims, UMR 7312, CNRS \\ Université de Reims Champagne-Ardenne, B.P. 1039, 51687 \\ Reims Cedex 2, France \\ jacques.muzart@univ-reims.fr \\ Click here to insert a dedication.
}

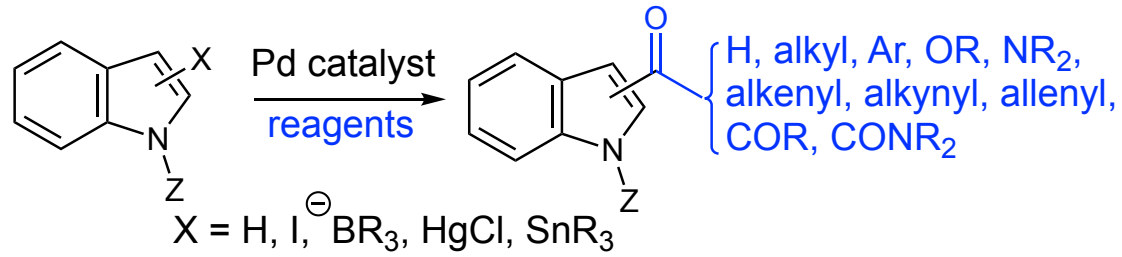

\begin{tabular}{|c|c|}
\hline $\begin{array}{l}\text { Receiv } \\
\text { Accept } \\
\text { Publish } \\
\text { DOI: }\end{array}$ & \\
\hline $\begin{array}{l}\text { Abstr } \\
\text { trans } \\
\text { indol } \\
\text { proce } \\
\text { subst } \\
\text { cases }\end{array}$ & $\begin{array}{l}\text { This review summarizes the Pd-catalyzed carbonylation, } \\
\text { lation and cross-coupling reactions which lead to carbonylated } \\
\text { om indoles and indolyl compounds. Special attention is drawn to } \\
\text { involving the } \mathrm{C}\left(\mathrm{sp}^{2}\right) \text { - } \mathrm{H} \text { substitution of free }(\mathrm{NH}) \text {-indoles or ( } \mathrm{N} \text { - } \\
\text { d)-indoles. Proposed mechanisms are described with, in some } \\
\text { sonal comments. }\end{array}$ \\
\hline 1 & Introduction \\
\hline 2 & Carbonylative reactions \\
\hline 2.1 & Indolyl halides as starting substrates \\
\hline 2.2 & Indolyl iodides as intermediates \\
\hline 2.3 & Indolyl borates as intermediates \\
\hline 2.4 & $\mathrm{C}\left(\mathrm{sp}^{2}\right)-\mathrm{H}$ reactions \\
\hline 2.4 .1 & Carboxylation \\
\hline 2.4 .2 & Carbonylative alkoxylation \\
\hline 2.4 .3 & Carbonylative arylation \\
\hline 2.4 .4 & Carbonylative alkenylation \\
\hline 2.4 .5 & Carbonylative alkylation \\
\hline 2.4.6 & Double carbonylation \\
\hline 3 & Stannyl- and mercurioindoles cross-couplings \\
\hline 4 & Cross-coupling of indoles with: \\
\hline 4.1 & Aldehydes \\
\hline 4.2 & Alcohols \\
\hline 4.3 & $\alpha$-Diketones \\
\hline 4.4 & $\alpha$-Oxo esters \\
\hline 4.5 & $\alpha$-Oxocarboxylic acids \\
\hline 4.6 & Nitriles \\
\hline 4.7 & Isocyanides \\
\hline 4.8 & Isothiocyanates and Isocyanates \\
\hline 4.9 & a-Amino carbonyl compounds \\
\hline 4.10 & Vinyl ethers or vinyl amides \\
\hline 4.11 & Toluene and substituted toluenes \\
\hline 4.12 & Bromodichloromethane \\
\hline 5 & Conclusion \\
\hline
\end{tabular}

\section{Introduction}

Indole chemistry received particularly strong interest due to the various biological and pharmaceutical properties of functionalized indoles. ${ }^{1,2}$ Palladium catalysis has been strongly involved in the preparation of indole derivatives. ${ }^{3}$ The Pdcatalyzed $\mathrm{C}\left(\mathrm{sp}^{2}\right)-\mathrm{H}$ substitutions of free $(\mathrm{NH})$-indoles and $(\mathrm{N}$ alkyl)-indoles occur predominantly at $\mathrm{C} 3$, while the $\mathrm{C} 2$-reactions mainly arise from indoles bearing a regiodirecting group at the nitrogen atom. Such chelation assistance may also lead to activation of the $\mathrm{C} 7-\mathrm{H}$ bond. The regioselectivity may nevertheless depend on the solvent, ${ }^{4}$ additives, ${ }^{5-7}$ ligands $^{8}$ and acidity of the reaction medium. ${ }^{9,10}$ Reaction at other positions requires indole derivatives as starting substrates. Significant investigations concerned the Pd-catalyzed functionalization of the indole nucleus with a carbonylated tether. They occur via carbonylation or cross-coupling reactions, and are the matter of the present review.

\section{Carbonylative reactions}

The Pd-catalyzed carbonylative functionalizations of indoles arise from interactions of $\mathrm{Pd}$ species with either an indole derivative or a $\mathrm{C}\left(\mathrm{sp}^{2}\right)-\mathrm{H}$ bond of the indolyl core.

\subsection{Indolyl halides as starting substrates}

Under an atmosphere of carbon monoxide, Pd catalysis and various experimental conditions, $\mathrm{N}$-unprotected and $\mathrm{N}$ protected iodo- or bromoindoles afford the corresponding carbonylpalladium complex which may evolve towards

- Carbaldehyde 1a by reduction with tri-n-butyltin hydride (Scheme 1), ${ }^{11}$

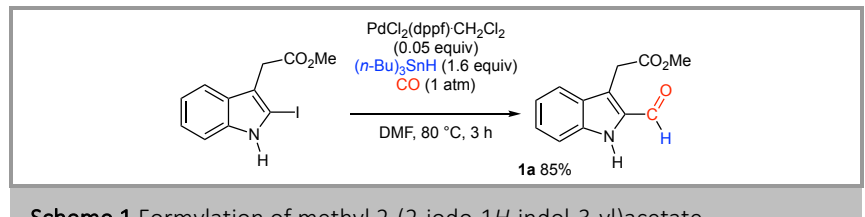

Scheme 1 Formylation of methyl 2-(2-iodo- $1 \mathrm{H}$-indol-3-yl)acetate

- $\quad$ Methyl ester 2a by methanolysis (Scheme 2),11 


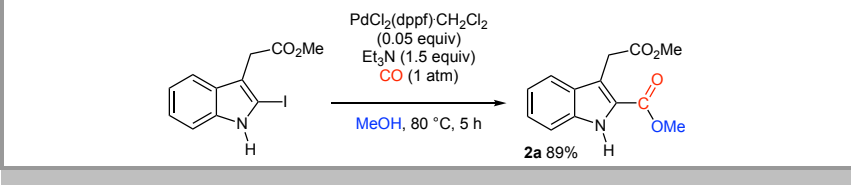

Scheme 2 Alkoxycarbonylation of methyl 2-(2-iodo- $1 \mathrm{H}$-indol-3-yl)acetate

- Ketones 3a, 4a and 5a-c by reaction with phenylboronic acid,12 (E)-tributyl(hex-1-en-1yl)stannane, ${ }^{11}$ or ethynyltrimethylsilane, respectively (Scheme 3). ${ }^{13}$

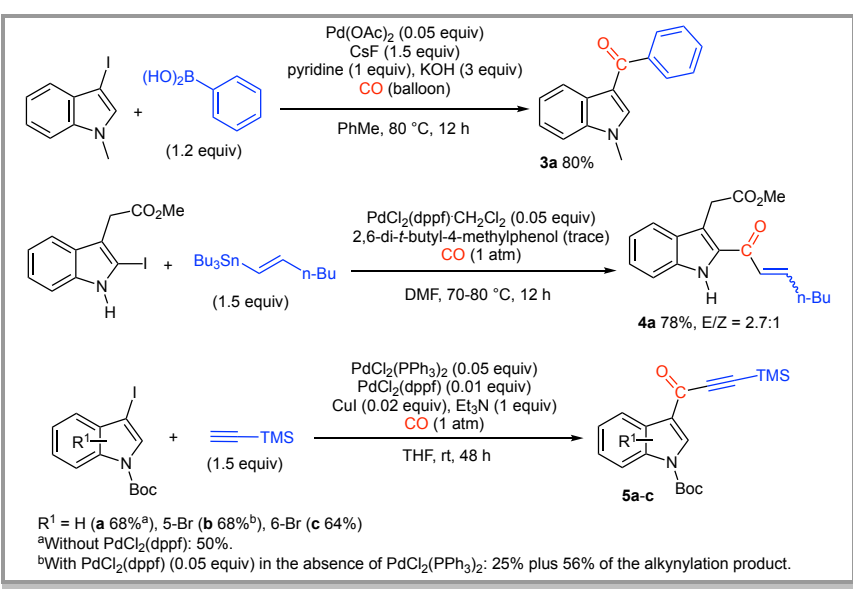

Scheme 3 Ketones from iodoindoles, $\mathrm{CO}$ and various reagents

or

Indolyl carboxamides $\mathbf{6 a - k}$ by reaction with a primary or secondary amine (Scheme 4).14 The strategy has been applied to the synthesis of ${ }^{11} \mathrm{C}$-radiolabelled amides $\mathbf{7 a}$ for positron emission tomography imaging (Scheme 4). ${ }^{15}$

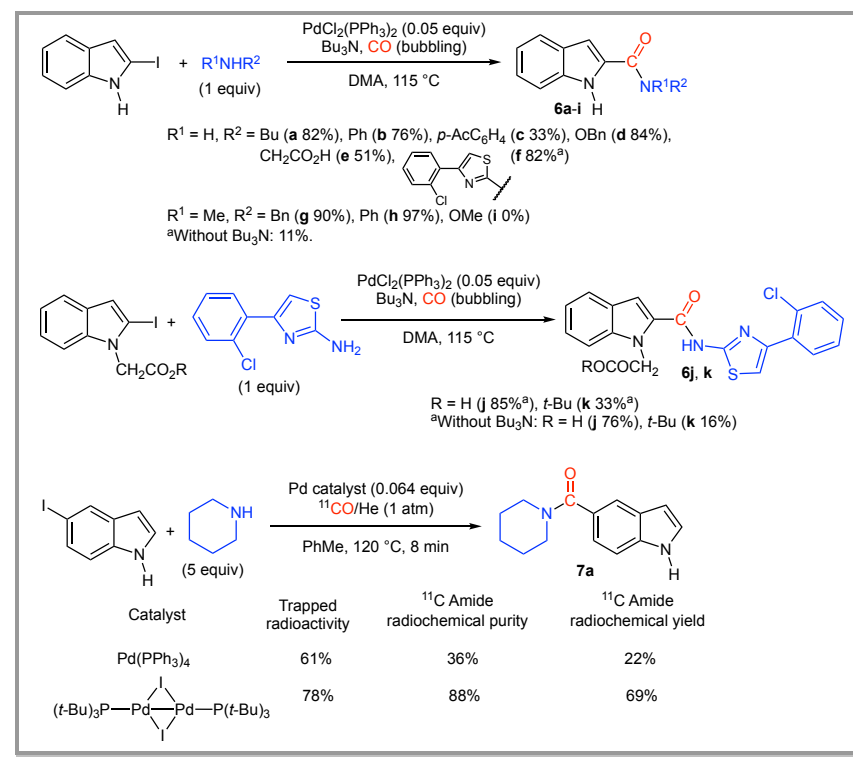

Scheme 4 Indolyl carboxamides from iodoindoles, CO and amines

Pd-catalyzed carboxylation, alkoxycarbonylation and aminocarbonylation of bromoindoles were performed under 25 bar CO pressure (Scheme 5), large yield decrease occurring under 10 bar pressure. 16

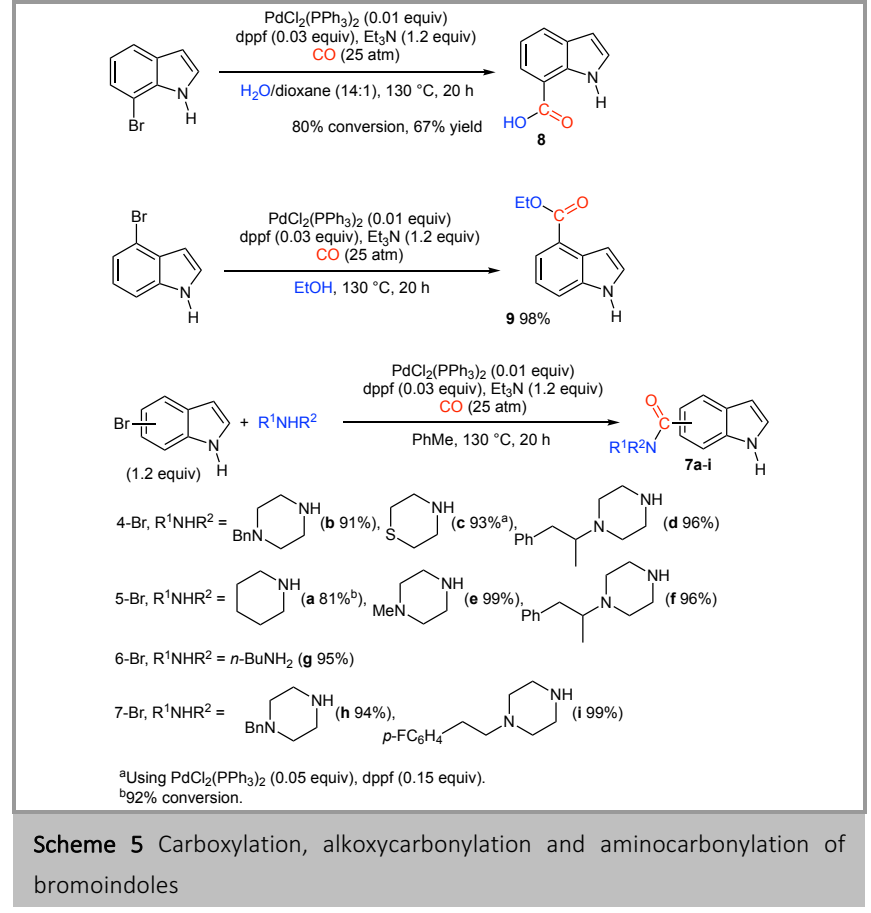

In the presence of diamines, palladium-catalysed carbonylation of 7-iodoindole under 10 bar CO pressure led mainly to carboxamide dimers $\mathbf{1 0}$ (Scheme 6). ${ }^{17}$

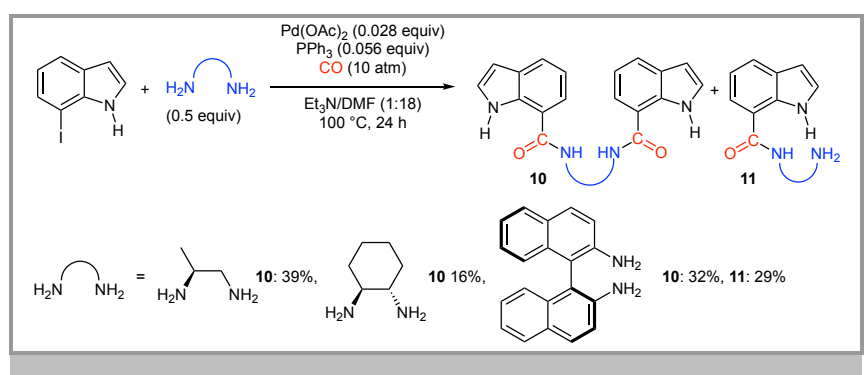

Scheme 6 Carboxamide dimers from 7-iodoindole, CO and diamines

$\alpha$-Ketoamides 12a, j-z, aa-ae were the major compounds obtained from the Pd-catalyzed reaction of unprotected iodoindoles using 40 bar CO pressure and a variety of amines except aniline, the low basicity of the latter leading mainly to the monocarbonylation coupling products 7 (Scheme 7). ${ }^{17}$ It is interesting to point out that the bromoaryl moiety of 5-bromo7-iodoindole remained intact under the used conditions (Scheme 7).

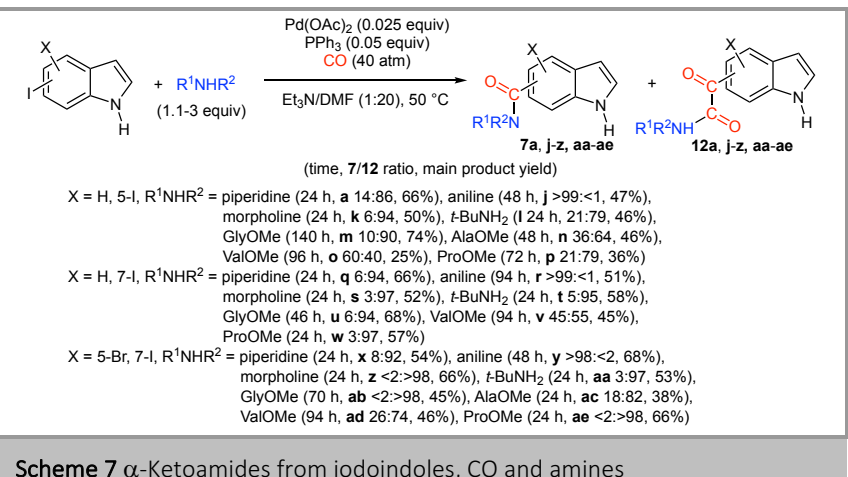

2.2. Indolyl iodides as intermediates 
Molecular iodine in a basic media has been used as one of the reagents of copper-catalyzed arylations of $\mathrm{C}\left(\mathrm{sp}^{2}\right)-\mathrm{H}$ bonds. ${ }^{18}$ Its role is the transformation of the $\mathrm{C}\left(\mathrm{sp}^{2}\right)-\mathrm{H}$ bond into the corresponding $\mathrm{C}\left(\mathrm{sp}^{2}\right)-\mathrm{I}$ bond which then reacts with the catalyst. This strategy has been applied to the Pd-catalyzed functionalization of the $\mathrm{C}(3)-\mathrm{H}$ of indoles through a domino iodination/carbonylation/cross-coupling reaction. Thus, $\mathrm{N}$ protected or unprotected indoles led to corresponding

- alkyl esters 13a-n and aryl esters 14a-q (Scheme 8), ${ }^{19}$ that methodology being conveniently applied to the synthesis of biologically active tropisetron $\mathbf{1 3 0}$ (Scheme 8), ${ }^{19}$

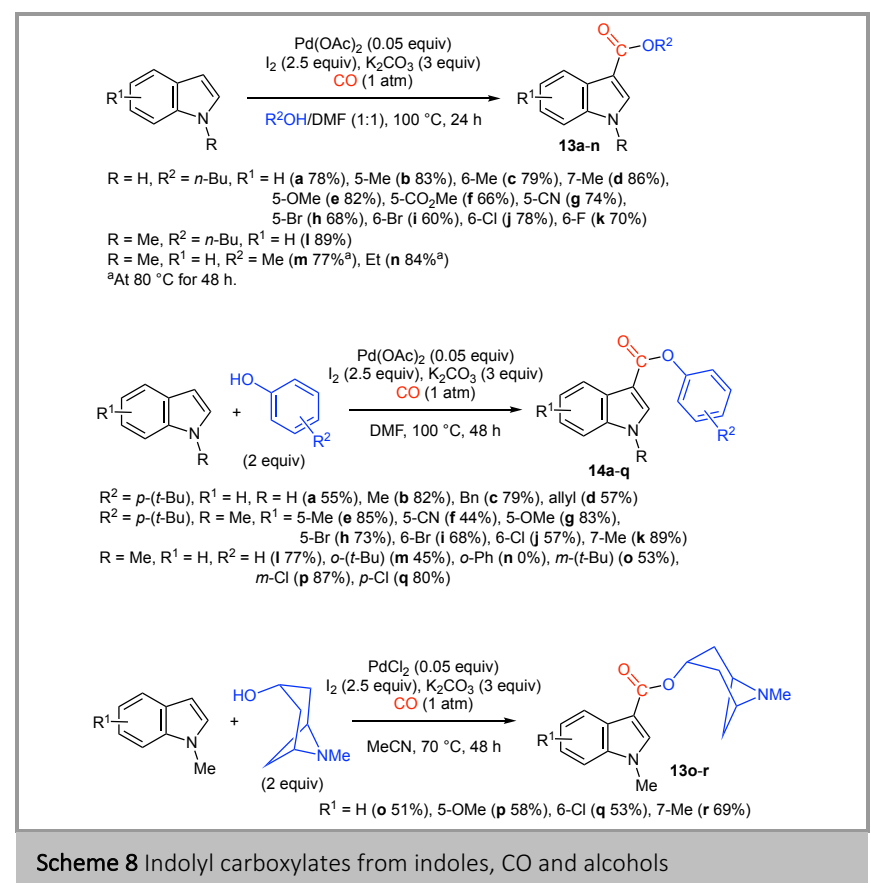

aryl ketones 3a-z, aa, ab $\mathbf{a b}^{12}$ and alkynones $\mathbf{5 d - z}$, aa-ap (Scheme 9), 20

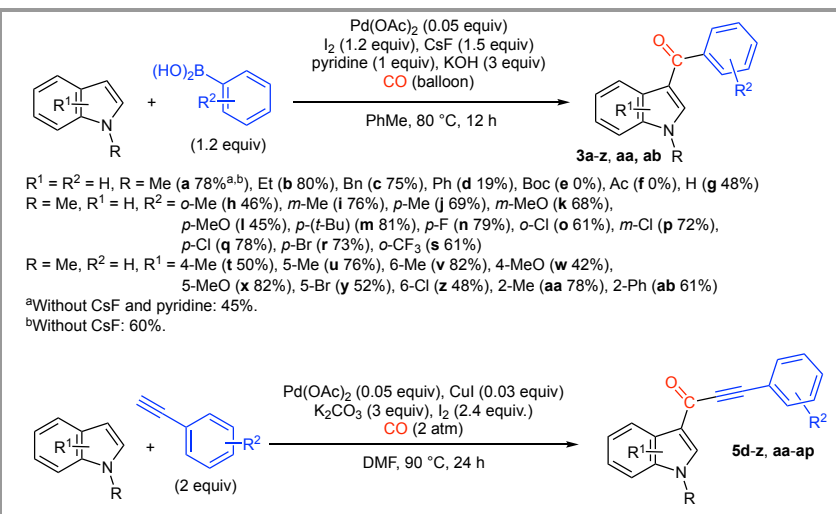

$\mathrm{R}^{1}=\mathrm{R}^{2}=\mathrm{H}, \mathrm{R}=\mathrm{Me}\left(\mathbf{d} 85 \% \mathrm{ab}, \mathrm{b}\right.$ ), $\mathrm{Bn}$ (e 84\%), allyl (f 86\%), $\mathrm{Ph}(\mathbf{g} 86 \%), p-\mathrm{MeC}_{6} \mathrm{H}_{4}(\mathbf{h} 77 \%)$, Ts (i $\left.0 \%\right)$

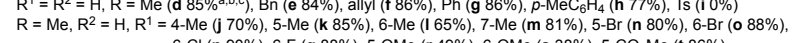

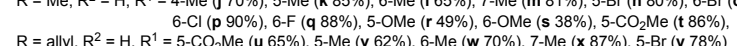

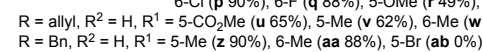

$\mathrm{R}=\mathrm{Bn}, \mathrm{R}^{2}=\mathrm{H}, \mathrm{R}^{1}=5-\mathrm{Me}(\mathbf{z} 90 \%), 6-\mathrm{Me}(\mathbf{a a} 88 \%), 5-\mathrm{Br}(\mathbf{a b} 0 \%)$
$\mathrm{R}=\mathrm{Me}, \mathrm{R}^{1}=\mathrm{H}, \mathrm{R}^{2}=\mathrm{H}(\mathbf{a c} 85 \%), p-\mathrm{Me}(\mathbf{a d} 78 \%), p-\mathrm{Et}(\mathbf{a e} 83 \%), p-(t-\mathrm{Bu})($ af $75 \%), p-\mathrm{F}($ ag $89 \%)$

$p$-OMe (ah 92\%), $m$-Me (ai 84\%)

$\mathrm{R}=\mathrm{Me}, \mathrm{R}^{1}=5-\mathrm{Me}, \mathrm{R}^{2}=p$-Me (aj 80\%), $p$-(t-Bu) (ak $\left.85 \%\right), p-\mathrm{F}(\mathbf{a l} 86 \%)$

$\mathrm{R}=\mathrm{Me}, \mathrm{R}^{1}=5-\mathrm{Br}, \mathrm{R}^{2}=p$-Me (am 90\%), $p$-(t-Bu) (an 92\%), $p$ - F (ao 63\%), p-OMe (ap 94\%)

aOther solvents: THF (48\%), PhMe (13\%), dioxane $(<5 \%)$,

Without Cul at $110^{\circ} \mathrm{C}: 73 \%$.

Scheme 9 Aryl and acetylenic ketones from indoles, CO and boronic acids or alkynes
- amides 15a-w, ${ }^{21}$ or $\alpha$-ketoamides 16a-u under increased CO pressure (Scheme 10). ${ }^{21}$

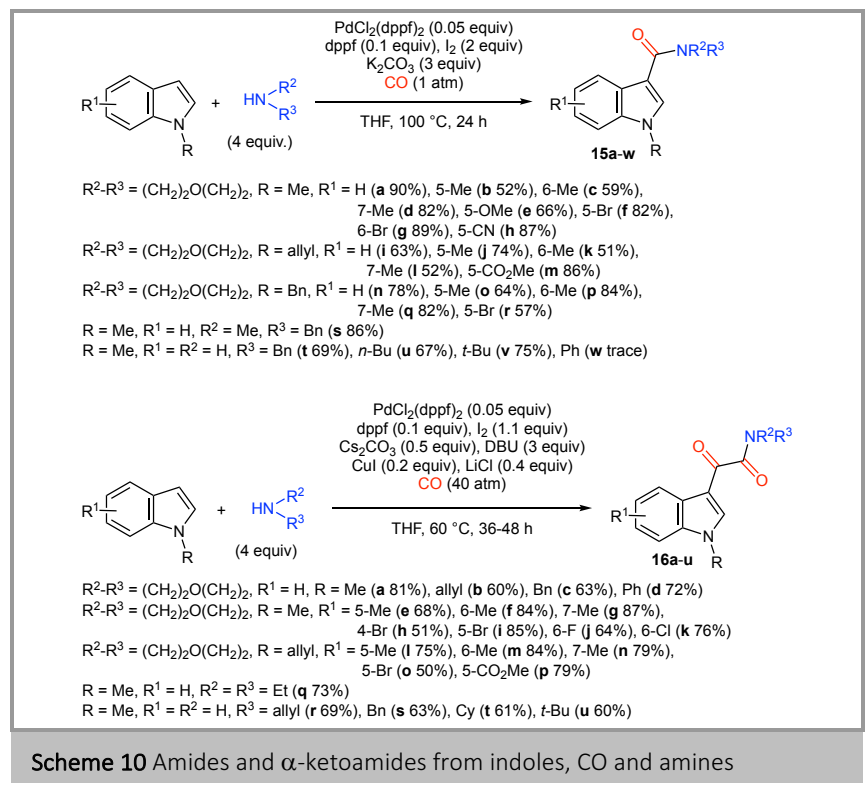

The use of copper iodide as co-catalyst for the synthesis of $\mathbf{5}$ and 16 could favor the iodination step. Indeed, the C3-iodination of indole with $\mathrm{CuI}$ has been recently reported. ${ }^{22}$ The formation of 3-iodo- $N$-methylindole $\mathbf{1 7}$ from $N$-methylindole under experimental conditions leading to $\mathbf{3}$ (Scheme 9) except the presence of an aromatic boronic acid (Scheme 11),12 and its reaction with $\mathrm{CO}$ and phenylboronic acid (Scheme 3) are consistent with 3 -iodoindoles as intermediates of the above domino reactions.

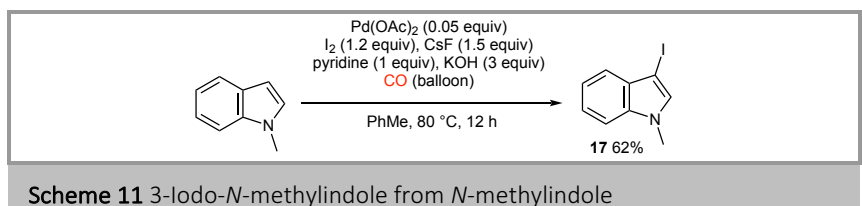

\subsection{Indolyl borates as intermediates}

In 1994, Ishikura and Terashima disclosed the one-pot reaction of $\mathrm{N}$-substituted indoles leading to 2-acyl derivatives $4 \mathbf{b}$-n via the Pd-catalyzed carbonylation of in situ produced indolylborates and the subsequent cross-coupling with aryl or alkenyl iodides as well as alkenyl triflates (Scheme 12). ${ }^{23}$ The procedure was then used for carbonylative cross-coupling with dienyl triflates providing a way to the total synthesis of yuehchukene 18 (Scheme 13). ${ }^{24}$ The latter would be a "lead compound for the design of drugs to treat antifertility and breast cancer". ${ }^{24}$ 


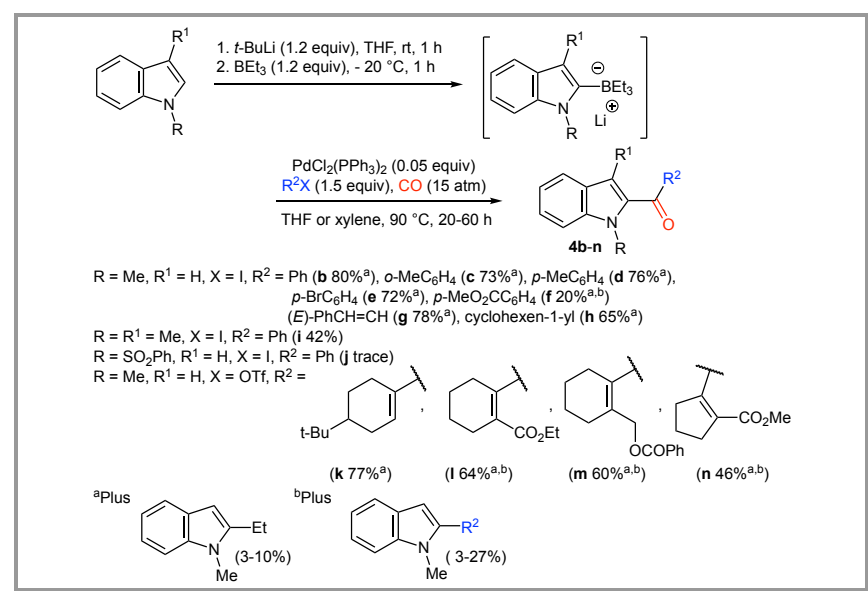

Scheme 12 Ketones from $\mathrm{N}$-substituted indoles, CO and aryl or alkenyl derivatives

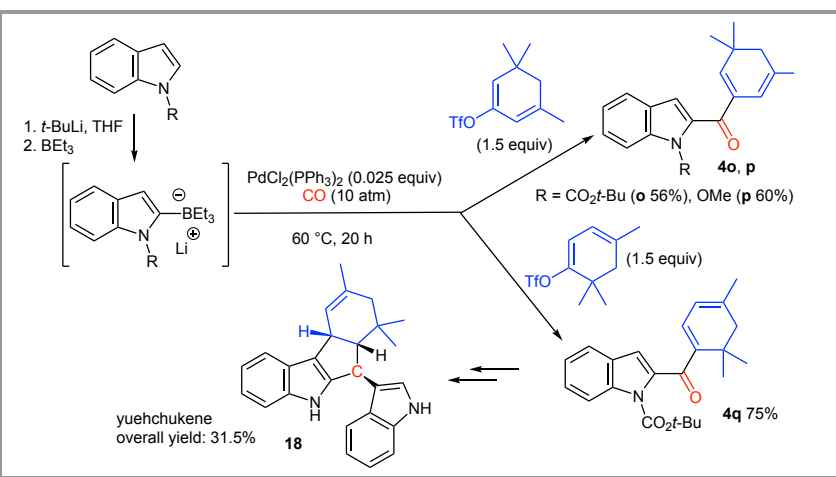

Scheme 13 Ketones from $\mathrm{N}$-substituted indoles, $\mathrm{CO}$ and dienyl triflates

Interestingly, $N$-methyl indole underwent a cascade reaction with prop-2-ynyl carbonates involving the intramolecular nucleophilic addition of the C3 carbon of indole to the internal allenic carbon, leading to cyclopenta $[b]$ indoles 19a, b (Scheme 14), which are basic frameworks of indole alkaloids..$^{25,26}$

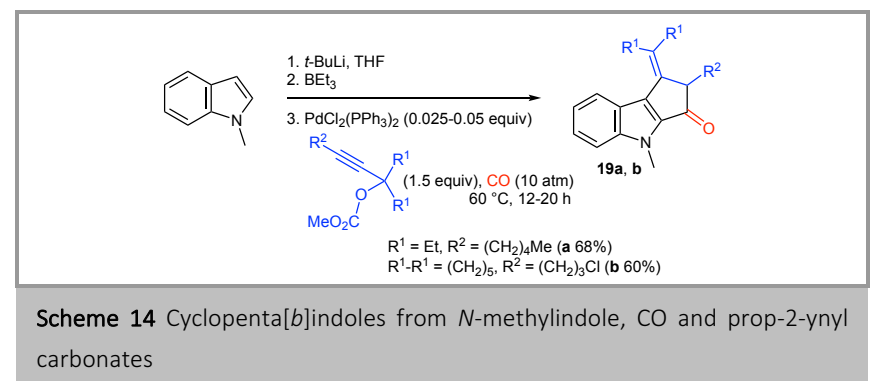

Susbtitution of the $\mathrm{N}$-atom with an electron withdrawing group suppressed the nucleophilicity of the C3-carbon, precluding the domino reaction, thus leading to allenyl ketones 20a-d (Scheme 15). ${ }^{26}$

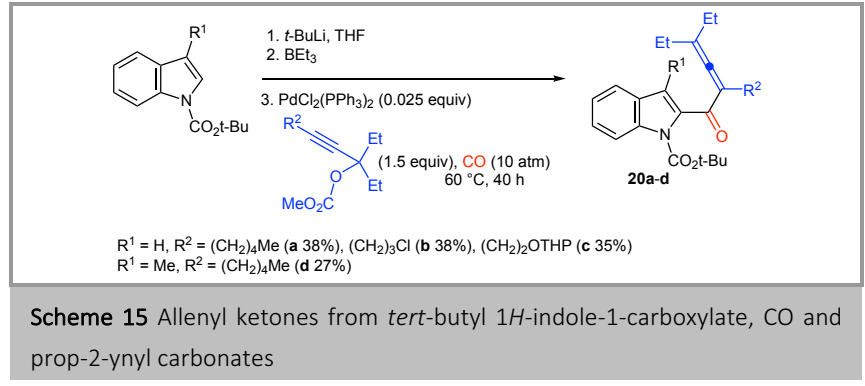

\section{4. $\mathrm{C}\left(\mathrm{sp}^{2}\right)-\mathrm{H}$ reactions}

\subsubsection{Carboxylation}

In 1982, Itahara disclosed the Pd-catalyzed C3-carboxylation of $\mathrm{N}$-acylindoles using carbon monoxide atmosphere in $\mathrm{AcOH}$, and sodium peroxydisulfate to regenerate active $\mathrm{Pd}^{\text {II }}$ species (Scheme 16). ${ }^{27}$ We suspect that the reaction mixture contained trace of water. Thus, the reaction would arise from $\mathrm{C} 3-\mathrm{H}$ activation leading to palladium indolyl complex ${ }^{16} \mathbf{A}$ (Scheme 16). Carbonylation of the latter affords ${ }^{\mathbf{1 6}} \mathbf{B}$, which undergoes hydrolysis to deliver product $\mathbf{2 1}$.

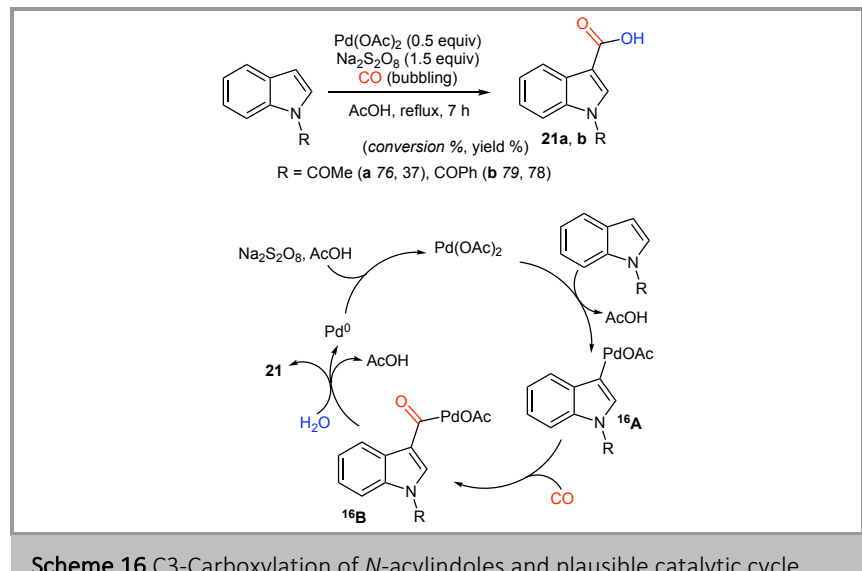

\subsubsection{Carbonylative alkoxylation}

In 2011, the teams of Xia- $\mathrm{Li}^{28}$ and $\mathrm{Lei}^{29}$ independently reported the C3-alkoxycarbonylation of $\mathrm{N}$-substituted indoles. Conditions similar to those of the above carboxylation (Scheme 16), except butanol as reagent and toluene as solvent, were inefficient, but shifting to a rhodium catalyst provided good yields of $\mathbf{1 3 1}$ (Scheme 17).28 An effective Pd procedure was nevertheless proposed by Lei and co-workers: various ethyl $N$-methyl(or benzyl)indole-3-carboxylates 13l, s-z, aa-ak were obtained in fair yields with $\mathrm{PdCl}_{2}\left(\mathrm{PPh}_{3}\right)_{2}$ as the catalyst and $\mathrm{Cu}(\mathrm{OAc})_{2} /$ air in DMSO/toluene (Scheme 18). ${ }^{29} \mathrm{~N}$-acetylindole was reluctant to react under the latter conditions (Scheme 18), while unprotected indoles underwent the $\mathrm{N}-\mathrm{H}$ alkoxycarbonylation to afford 22a-h (Scheme 18). ${ }^{29}$ The C3-alkoxycarbonylation occurs via the alcoholysis of II. Apparently, DMSO is involved in the regeneration of active $\mathrm{Pd}^{\mathrm{II}}$ species, its absence provoking a drastic yield depreciation (Scheme 18). Such a role of DMSO has been initially disclosed by Larock's team. ${ }^{30}$ 


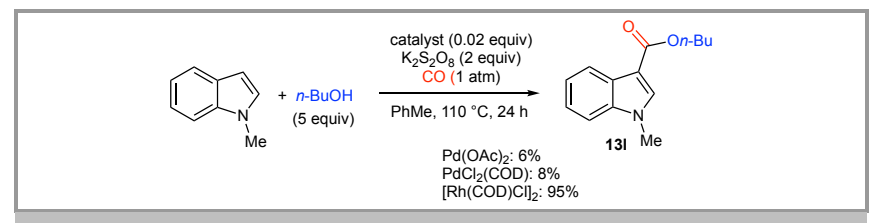

Scheme 17 Rhodium-catalyzed alkoxycarbonylation of $\mathrm{N}$-methylindole

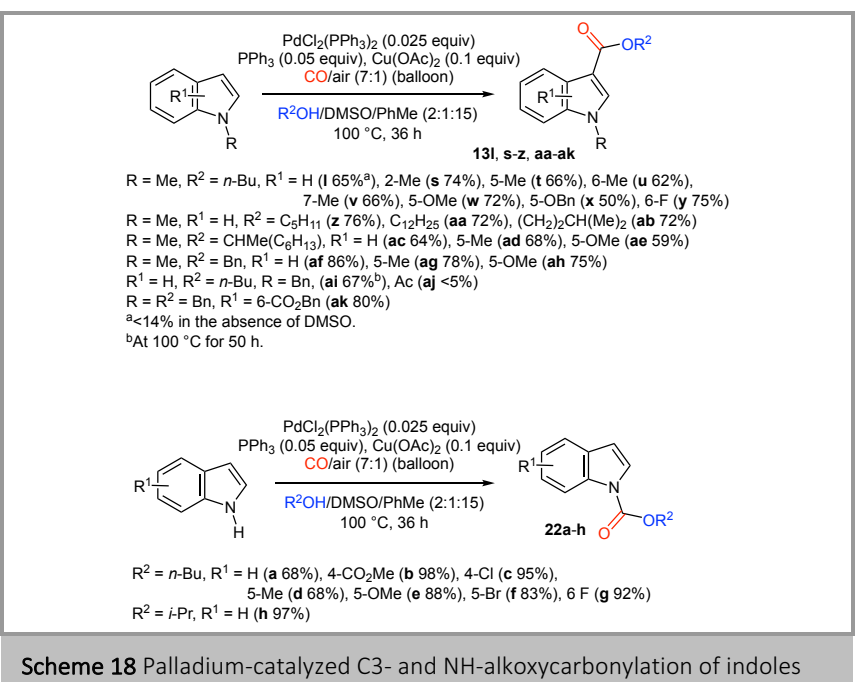

\subsubsection{Carbonylative arylation.}

In 2015, Arndtsen and Tjutrins disclosed the synthesis of 3aroyl $N$-phenyl(or benzyl)indoles 3ac-aj from the $\mathrm{Pd}\left(\mathrm{P} t-\mathrm{Bu}_{3}\right)_{2}$ catalyzed reaction of corresponding $N$-substituted indoles with carbon monoxide and aryl iodides (Scheme 19).31,32 A one-pot reaction generating polycyclic compound $\mathbf{2 3}$ was carried out with $o$-bromoiodobenzene as arylating agent, the carbonylative C-H functionalization being followed by an intramolecular Heck reaction (Scheme 19).

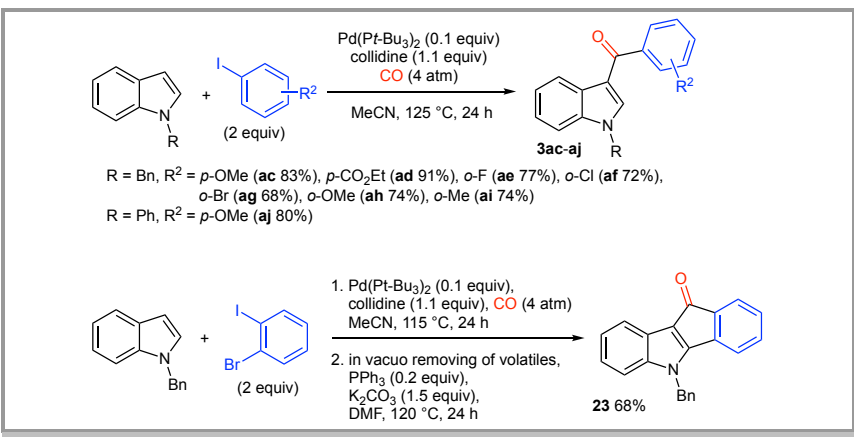

Scheme 19 Ketones and cyclic ketones from $\mathrm{N}$-substituted indoles, $\mathrm{CO}$ and aryl iodides

Three plausible reactive pathways were retained for the carbonylative arylation (Scheme 20);31 the palladium aroyl complex ${ }^{20} \mathbf{A}$ formed as intermediate could

- lead to aroyl iodide ${ }^{20} \mathbf{B}$ which would add to the substrate (path $a$ ),

- $\quad$ suffer addition of the substrate to its aroyl ligand (path $b$ ),
- undergo a reaction analog to the Pd-catalyzed arylation of indoles (path c).

The authors assumed that IV reacts with PdLn rather than with the substrate, hence a disadvantage for path $a$. We suggest that path $c$ can be discarded because the Pd-catalyzed arylation of $N$ methylindole with phenyl chloride 33 or $p$-bromotoluene ${ }^{34}$ occurred selectively or mainly in $\mathrm{C} 2$ position. Path $c$ also disagrees with the recent report of the absence of coupling between $\mathrm{N}$-methylindole and nonanoyl chloride in the presence of catalytic amounts of $\mathrm{PdCl}_{2}$, Xantphos and $p$-TsOH at $120{ }^{\circ} \mathrm{C}$ in $\mathrm{PhMe}^{35}$ The formation of the C3-substituted product $\mathbf{3}$ from Friedel-Crafts acylation of $N$-substituted indoles ${ }^{34,36}$ is consistent with path $b$.

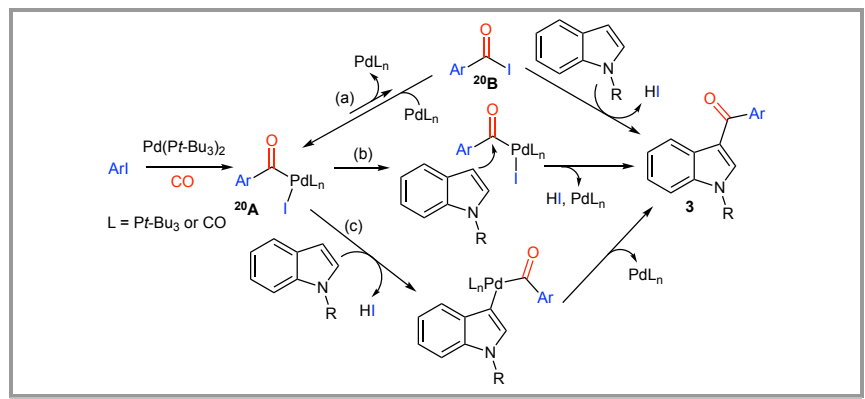

Scheme 20 Proposed mechanisms for the carbonylative arylation reaction

\subsubsection{Carbonylative alkenylation}

A number of catalytic systems was tested by Alper and Zeng to perform the coupling of indoles with carbon monoxide and methyl or ethyl propiolates. ${ }^{37}$ Except from $N$-acetylindole, good yields of $\alpha, \beta$-unsaturated ketones 24a-i, k-q were obtained using a cationic complex, $\mathrm{Pd}(\mathrm{MeCN})_{4}\left(\mathrm{BF}_{4}\right)_{2}$, associated to Xantphos (Scheme 21). The catalyst may also promote the subsequent addition of the substrate to the $\alpha, \beta$-unsaturated ketone, giving compound 25. Mechanism studies using $\mathrm{N}$ methyl-3-D-indole and methyl 3-D-propiolate led to propose the formation of the active cationic palladium hydride complex ${ }^{\mathbf{2 1}} \mathrm{A}$ (Scheme 21). ${ }^{38}$ According to the deuterium distribution in deuterium-labeling reactions, two parallel pathways - $a$ and $b$ are responsible for the formation of the alkenylpalladium intermediate ${ }^{21 \mathbf{B}}$. Carbonylation of the latter followed by nucleophilic attack of the indole affords ${ }^{21}$ C. Subsequent rearomatization of the indole unit provides $\mathrm{Pd}^{\mathrm{IV}}$ complex ${ }^{21} \mathbf{D}$, which is reduced to ${ }^{\mathbf{2 1}} \mathbf{A}$ by forming product $\mathbf{2 4}$. 


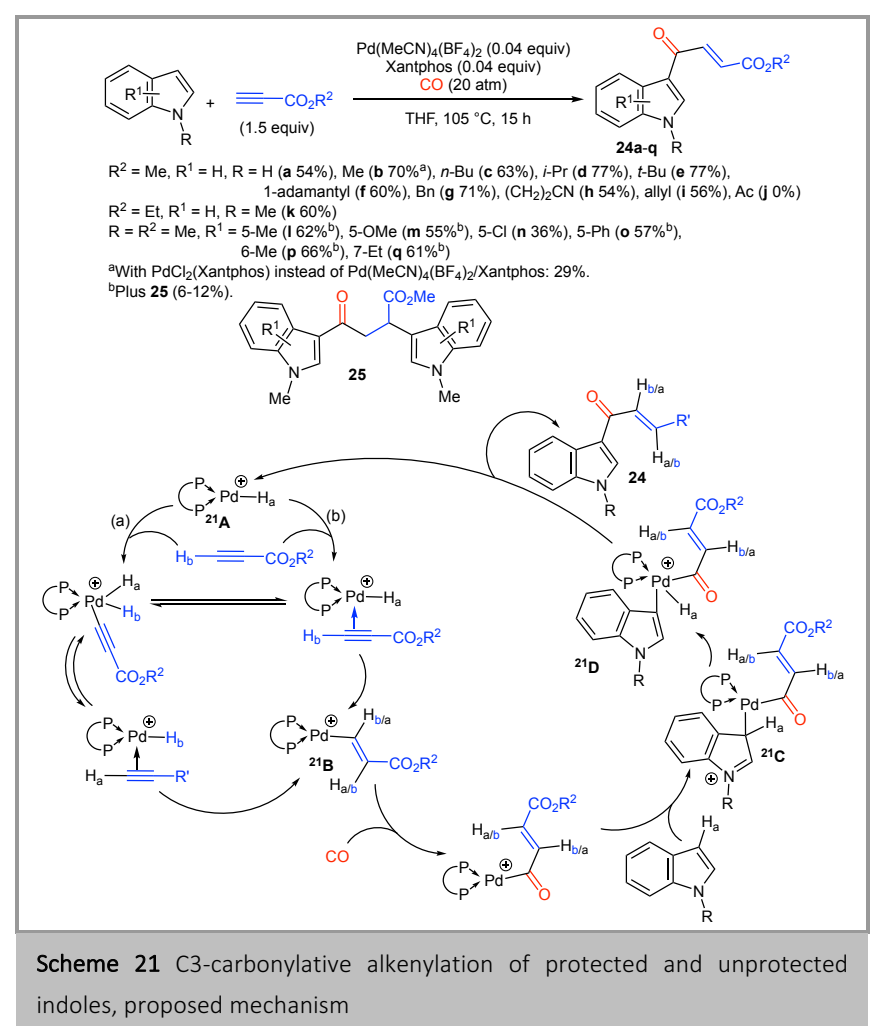

\subsubsection{Carbonylative alkylation.}

Recently, Beller and co-workers reported the C3-acylation of $\mathrm{N}$ methyl(or benzyl)indoles with carbon monoxide and alkenes using catalytic amounts of $\mathrm{PdCl}_{2}$, Xantphos and $p$-TsOH in toluene (Scheme 22).35 Low amounts of the C2-acylation product were detected. Such a coupling product was efficiently obtained from 1,3-dimethylindole (Scheme 23).
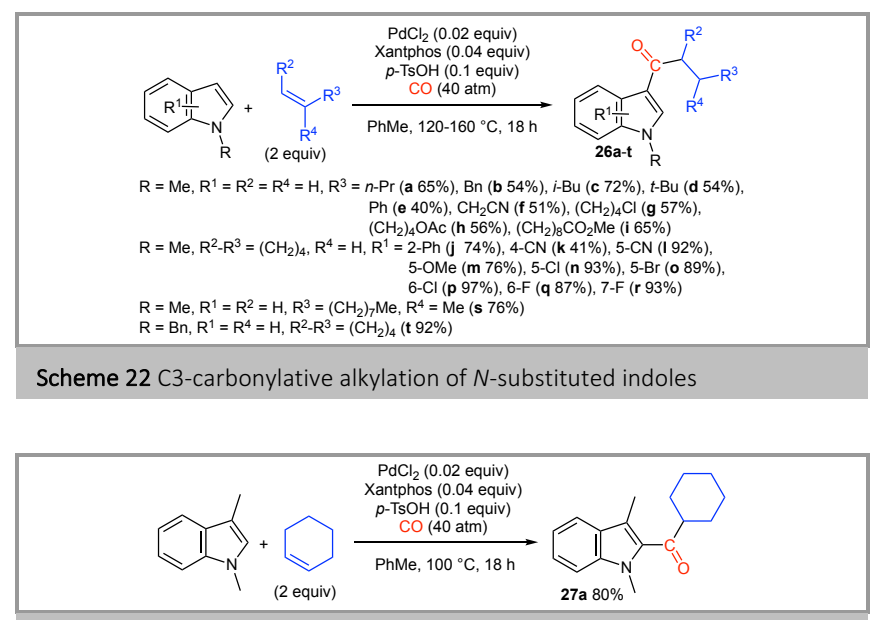

Scheme 23 C2-carbonylative alkylation of 1,3-dimethylindole

The authors envisaged three catalytic cycles leading to the C3acylation. Two of them involve the reduction of $\mathrm{PdCl}_{2}$ by the phosphine and subsequent reaction with $p$-TsOH to provide the hydride complex ${ }^{24} \mathbf{A}$ (Scheme 24). Coordination of the alkene to ${ }^{24} \mathbf{A}$ leads to alkylpalladium intermediate ${ }^{24} \mathbf{B}$ which coordinates CO to afford acylpalladium complex ${ }^{24} \mathbf{C}$. The product would be obtained from ${ }^{24} \mathbf{C}$ via either nucleophilic attack of the indole (Scheme 24, path $a$ ) as depicted in Schemes 20 (path $b$ ) and 21, or formation of the acyl halide or acid followed by Friedel-Crafts reaction (Scheme 24, path $b$ ). Pathway $b$ was discarded because the coupling product was not detected using nonanoyl chloride or acid instead of the corresponding alkene under the same experimental conditions. The third suspected catalytic cycle started with PdII-mediated $\mathrm{C} 3-\mathrm{H}$ activation of the indole to afford the 3-indolyl palladium complex as depicted in Scheme 16. After reaction of the latter with $\mathrm{CO}$ and the alkene, protonolysis will give the product. Kinetic experiments have shown that, in contrast to $\mathrm{Pd}^{0}, \mathrm{Pd}^{\mathrm{II}}$ catalyst led to a large induction period. These results are incompatible with the initial $\mathrm{C}-\mathrm{H}$ activation of the indole. Thus, the most likely pathway is, as for the above carbonylative arylation and alkenylation, the nucleophilic attack of the indole to the cationic acylpalladium complex (Scheme 24, path $a$ ).

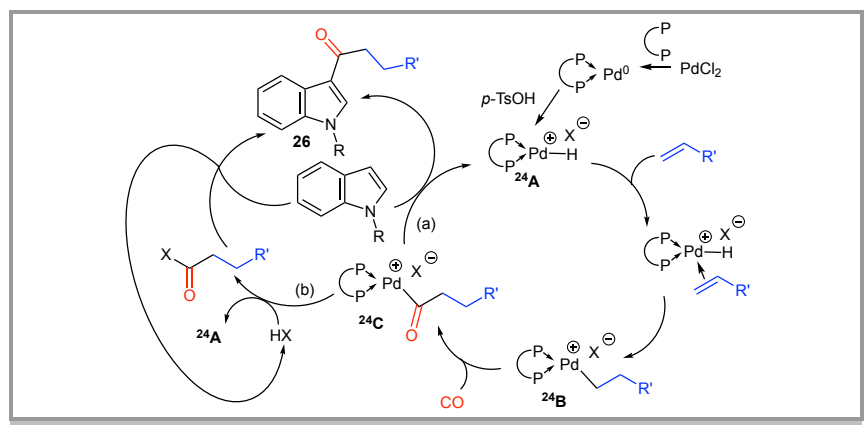

Scheme 24 Proposed catalytic cycle for the carbonylative alkylation reaction

The Pd-catalyzed reaction between $N$-methylindole, $\mathrm{CO}$ and allyl alcohol afforded tricyclic ketone $\mathbf{2 8}$ (Scheme 25). That occurs through C3-allylation ${ }^{39,40}$ and subsequent intramolecular carbonylation..$^{35}$

Scheme 25 9-Methylhexahydrocarbazolone from $\mathrm{N}$-methylindole, $\mathrm{CO}$ and
allyl alcohol

\subsubsection{Double carbonylation}

Recently, the double carbonylation of indole leading to methyl 2-(1H-indol-3-yl)-2-oxoacetate 29a was reported by Wu and coworkers. ${ }^{41}$ Various $\mathrm{Pd}$ and $\mathrm{Cu}$ catalysts were efficient with hexaketocyclohexane octahydrate as the $\mathrm{CO}$ source, $\mathrm{CuBr}(\mathrm{SMe})_{2}$ providing the best yield (Scheme 26). Transition metalcatalyzed decomposition of hexaketocyclohexane in the presence of methanol would afford carbon monoxide and carboalkoxy complex ${ }^{26} \mathbf{A}$. Transmetalation of the latter with alkoxy complex ${ }^{26} \mathbf{B}$ leads to ${ }^{26} \mathbf{C}$; subsequent reductive elimination produces the double carbonylation product. 


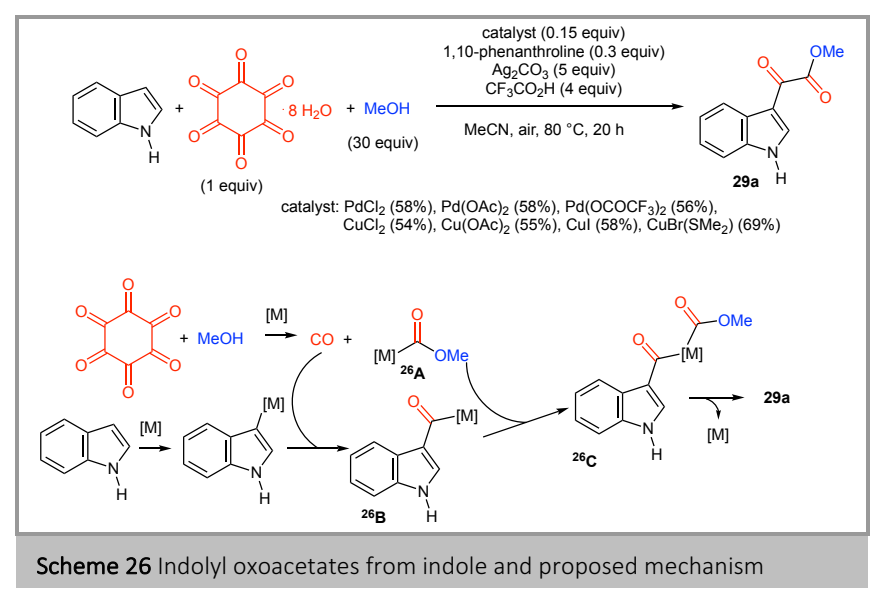

\section{Stannyl- and mercurioindoles cross-couplings}

In 1989, Hegedus team disclosed the two steps-synthesis of 4bromo-3-acryloyl-1-tosylindole 24r (Scheme 27).42 4-Bromo-1tosylindole was firstly transformed into the mercurioindole 30.43 Treatment of the latter with acryloyl chloride and catalytic $\mathrm{Pd}\left(\mathrm{PPh}_{3}\right)_{4}$ led to 24 r. That occurs via oxidative addition of the acid chloride to $\mathrm{Pd}^{0}, \mathrm{Hg}^{\mathrm{II}} / \mathrm{Pd}^{\mathrm{II}}$ transmetalation and reductive elimination. ${ }^{42,44}$

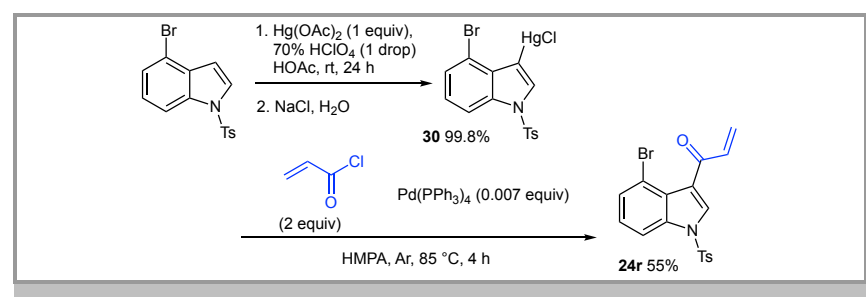

Scheme 27 Indolyl propanone from 4-bromo-3-acryloyl-1-tosylindole

2-Aroylindoles $\mathbf{4 r - u}$ and 2-(arylacetyl)indoles 27b-f were obtained via Pd-catalyzed cross-couplings of aroyl chlorides or arylacetyl chlorides with $N$-substituted indol-2-ylstannanes 31a-c obtained from lithiation of the corresponding indoles, and subsequent trapping of the 2-lithio species with a trialkyltin chloride $^{45}$ (Schemes 28). ${ }^{46,47}$ Such procedures involve also transmetalation and subsequent reductive elimination of $\mathrm{Pd}^{0}{ }^{0.8}$

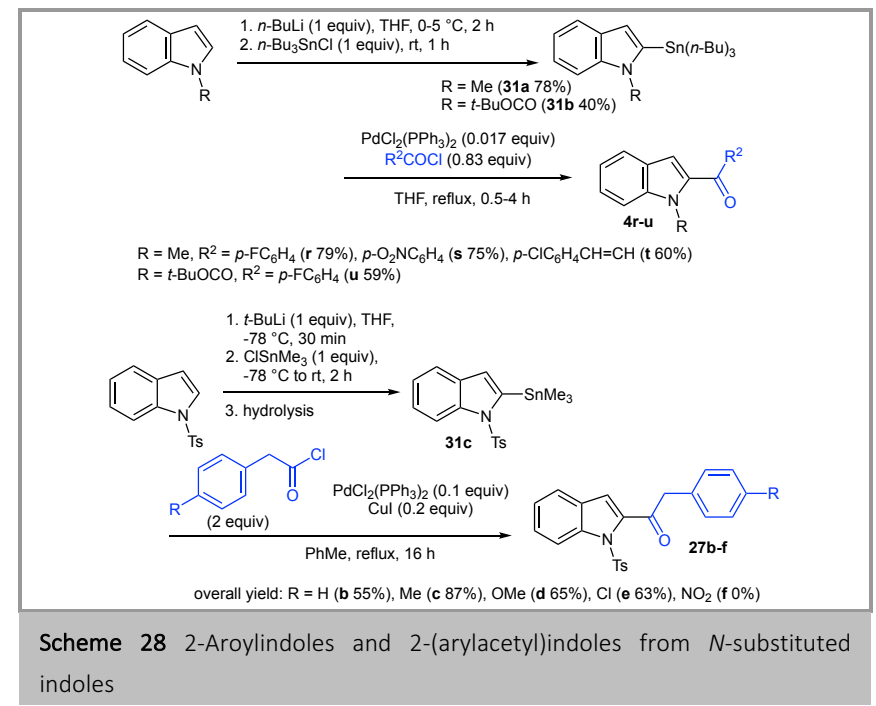

\section{Cross-coupling of indoles with:}

\subsection{Aldehydes}

In 2013, Kianmehr and co-workers reported the $\mathrm{Pd}(\mathrm{OAc})_{2}$ catalyzed the C3-aroylation of $N$-alkyl(or aryl)indoles using benzaldehydes and $t$-BuOOH at $140{ }^{\circ} \mathrm{C}$ in chlorobenzene (Scheme 29).49 Efficiency of the process greatly decreased using other solvents, peroxides or catalysts.

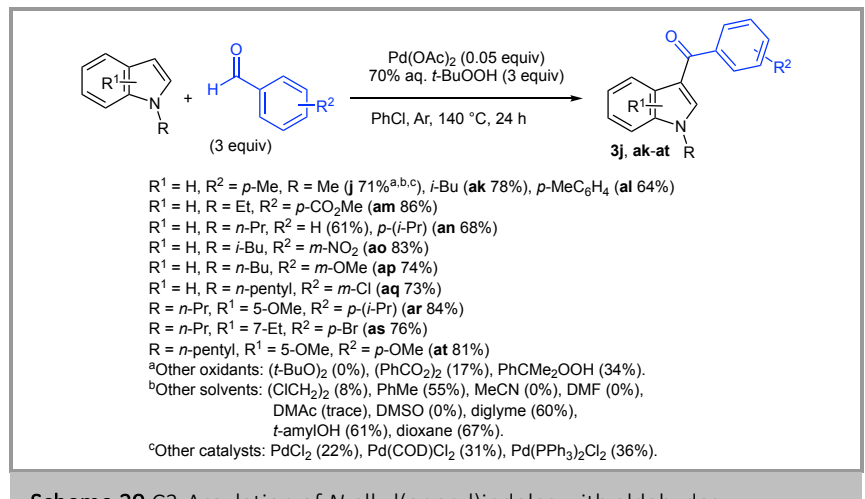

Scheme 29 C3-Aroylation of $\mathrm{N}$-alkyl(or aryl)indoles with aldehydes

A few months later, the C2-acylation was disclosed by Liu's team using a 2-pyridinyl or 2-pyrimidinyl directing group and again $t$ $\mathrm{BuOOH}$ as the most optimal oxidant (Scheme 30).50 The reaction was carried at $80^{\circ} \mathrm{C}$ in toluene, with pivalic acid as additive to improve the efficiency. The latter may stabilize Pd-indole species ${ }^{10}$ and may inhibit side reactions..$^{51}$

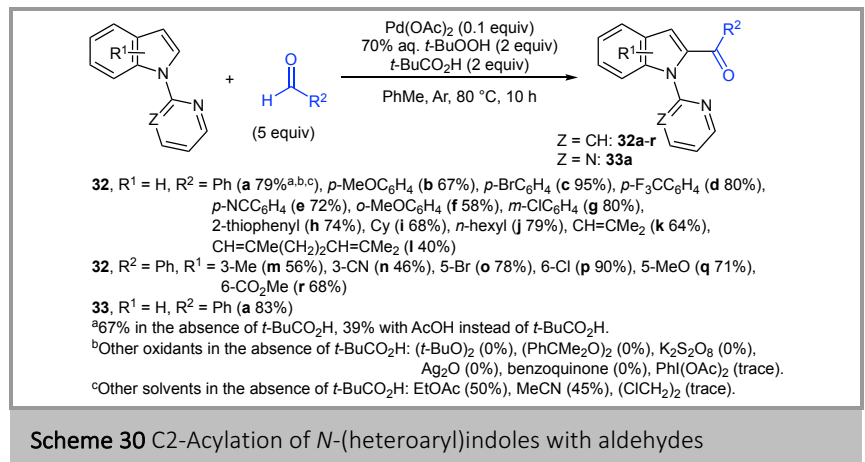

$\mathrm{Pd}(\mathrm{OAc})_{2}$ catalysis, anhydrous $t$-BuOOH and a variety of aldehydes were then used in the absence of pivalic acid for the C2-acylation of

- $\quad N$-(pyridin-2-yl)indoles in 1,2-dichloroethane or chlorobenzene at $80^{\circ} \mathrm{C}$ (Scheme 31), ${ }^{52}$

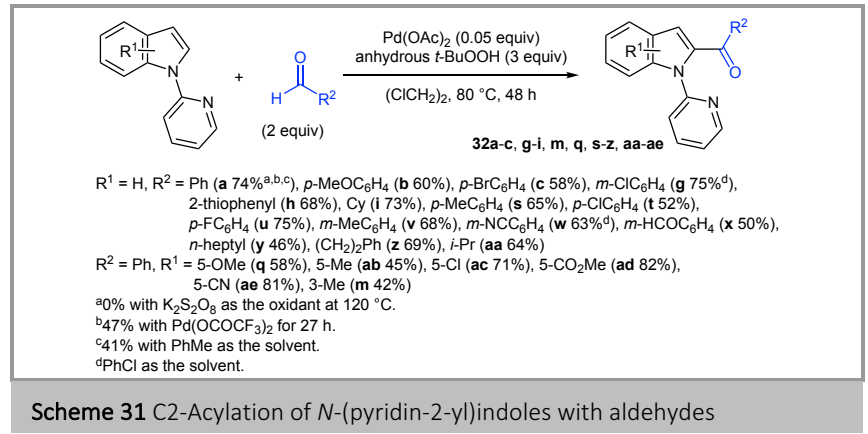


- $\quad N$-(pyrimidin-2-yl)indoles in ethyl acetate at $125{ }^{\circ} \mathrm{C}$ (Scheme 32), ${ }^{53}$

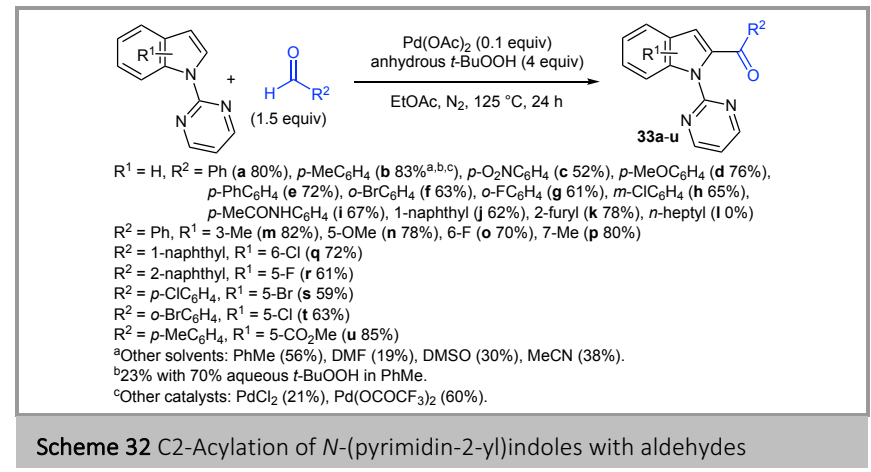

and

$N$-(pyridin-2-yl)indoles and $N$-(pyrimidin-2-yl)indoles at room temperature in acetonitrile under visible light photoredox assistance (Scheme 33). 54,55

As above exemplified, the yields strongly depend on the experimental conditions.

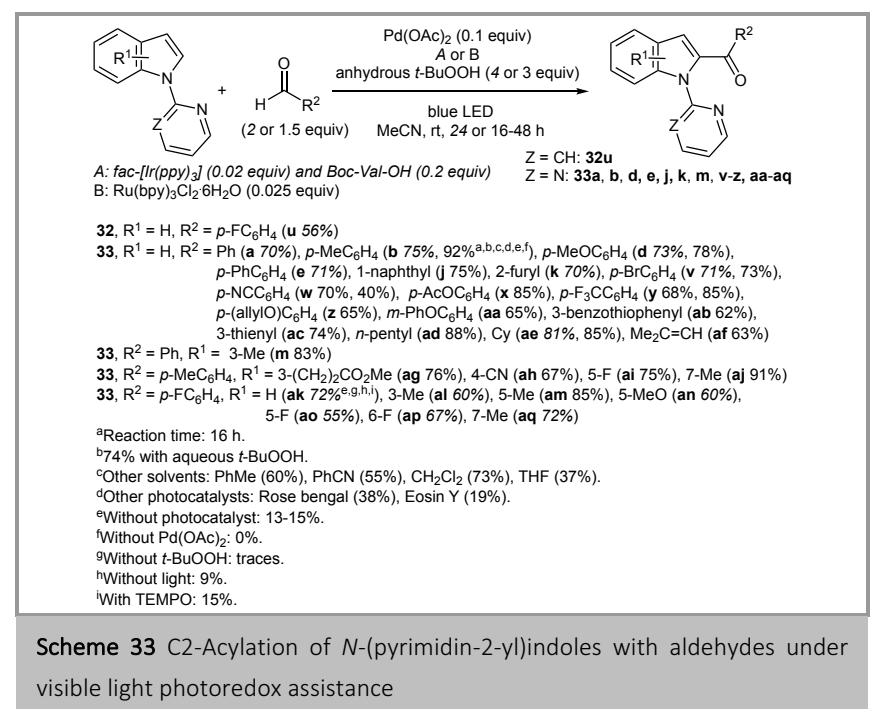

$N$-(Pyridin-2-yl)indoles 34a-d aroylated in 2 and 7 positions have been synthesized using the $\mathrm{Pd}(\mathrm{OAc})_{2} / t-\mathrm{BuOOH}$ system as well (Scheme 34). ${ }^{2}$

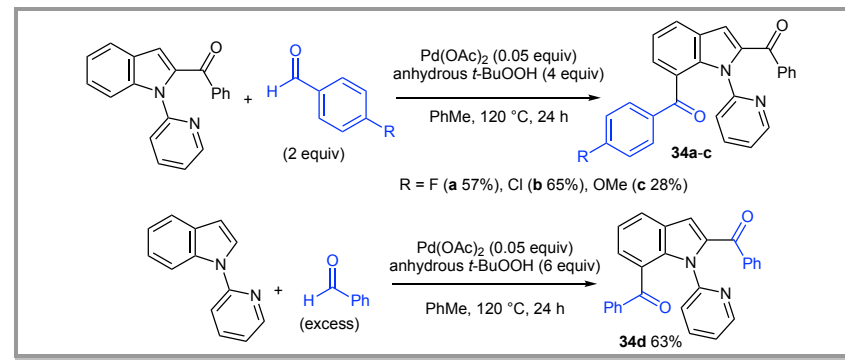

Scheme 34 C2 and C7-Aroylation of $N$-(pyridine-2-yl)indoles with aldehydes

In contrast to the above low efficiency of the $\mathrm{PdCl}_{2}$-catalyzed aroylations (Schemes 29 and 32), Sekar and Kumar obtained better results in the C2-acylation of $N$-(pyrimidin-2-yl)indoles with $\mathrm{PdCl}_{2}$ instead of $\mathrm{Pd}(\mathrm{OAc})_{2}$ as the catalyst (Scheme 35). ${ }^{56}$
They also carried out the C2,C7-diacylation using a threefold excess of aldehyde (Scheme 36).

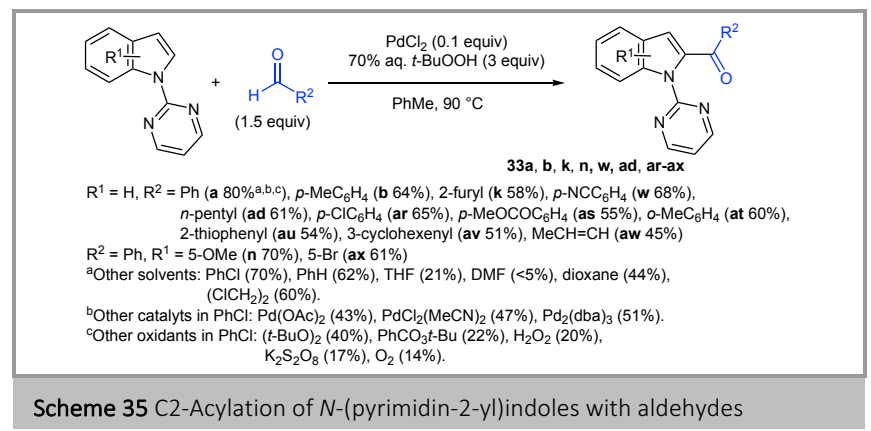

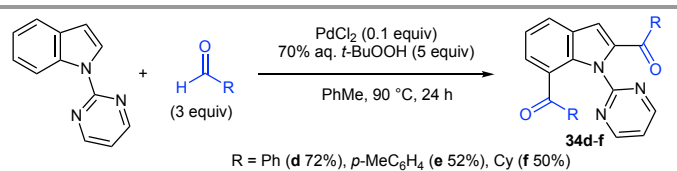

Scheme 36 C2,C7-Diacylation of $\mathrm{N}$-(pyrimidin-2-yl)indoles with aldehydes

The C7-benzoylation of ethyl 2-methyl-1-(pyrimidin-2-yl)- $1 \mathrm{H}$ indole-3-carboxylate was performed using $\mathrm{Pd}\left(\mathrm{OCOCF}_{3}\right)_{2}$ as the catalyst in 1,2-dichloroethane (Scheme 37). ${ }^{57}$

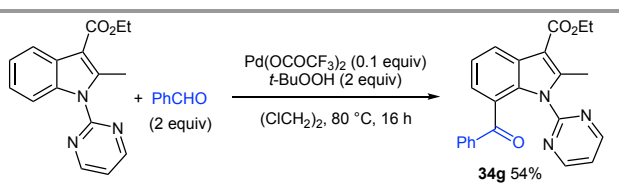

Scheme 37 C7-Benzoylation of ethyl 2-methyl-1-(pyrimidin-2-yl)- $1 \mathrm{H}$-indole-3carboxylate with benzaldehyde

In the absence of a chelating substituent, the reaction occurs via the complex I (Scheme 16) ${ }^{49}$ while ligation of the 2-pyridinyl or 2-pyrimidinyl group to palladium directs towards the formation of chelated complex ${ }^{\mathbf{3 8}} \mathbf{A}$ (Scheme 38). ${ }^{50,52-55}$ The latter reacts with acyl radical ${ }^{38} \mathbf{B}$ which is formed from the reaction of the aldehyde with tert-butoxy ${ }^{49,50,53}$ or hydroxy53,58 radical. Heatmediated homolytic cleavage of $t$ - $\mathrm{BuOOH}$ leads to these two radicals, $, 0,53,58$ - $\mathrm{BuO}$ may also be produced at room temperature via the oxidation of the excited state of $\operatorname{Ir}^{3+}$ or $\mathrm{Ru}^{2+}$ by $t$-BuOOH (Scheme 38). ${ }^{54,55}$ The proposal of acyl radical ${ }^{38} \mathbf{B}$ is consistent with its trapping with radical scavenger TEMPO, 54,55 leading to concomitant large decrease of yields. ${ }^{50,53,55}$ According to the Van der Eycken and Jana teams, the reaction of ${ }^{38} \mathbf{A}$ with ${ }^{38} \mathrm{~B}$ leads to PdIII complex ${ }^{38} \mathrm{C}$ which is oxidized with the photoredox system into $\mathrm{Pd}^{\mathrm{IV}}$ complex ${ }^{38} \mathbf{D}$ (path $a$ ). Subsequent reductive elimination affords products $32-33$ and active $\mathrm{Pd}^{\mathrm{II}}$ species. ${ }^{54,55}$ The other procedures were also carried out with $t$ $\mathrm{BuOOH}$, but at $80-140{ }^{\circ} \mathrm{C}$ instead of both room temperature and photoredox assistance. Kianmehr and co-workers assumed that, under these conditions, ${ }^{38} \mathbf{A}$ would react with ${ }^{38} \mathbf{B}$ "to afford the $\mathrm{Pd}^{\mathrm{IV}}$ intermediate" (path $b$ ). ${ }^{49}$ They nevertheless involved $\mathrm{AcOH}$ in the regeneration of the PdII catalyst. ${ }^{49}$ According to Zhang's team which studied different acylation reactions, a $\mathrm{Pd}^{\mathrm{IV}}$ species could be formed from the addition of both acyl and $t$-butoxy radicals to a PdII complex. ${ }^{58}$ Liu and co-workers also proposed contribution of the acid in the catalyst regeneration ${ }^{50}$ but, like the teams of Zhang and Tan, ${ }^{52,53}$ they noted that III or IV would 
be the plausible oxidation state of the acyl palladium complex delivering the product. Thus, the mechanism remains a matter of debate. We suspect that the role of $t$-BuOOH under photoredox-free conditions is not limited to the formation of 38B: it could participate in the regeneration of the catalyst and, if any, in the formation of the $\mathrm{Pd}^{\mathrm{IV}}$ intermediate. Apparently, the presence of the acylating agent precludes the oxidation of the indole into the corresponding isatin $\mathbf{3 5}$, a reaction subsequently reported with ${ }^{59}$ and without ${ }^{60} \mathrm{Pd}$ catalysis (Scheme 39).
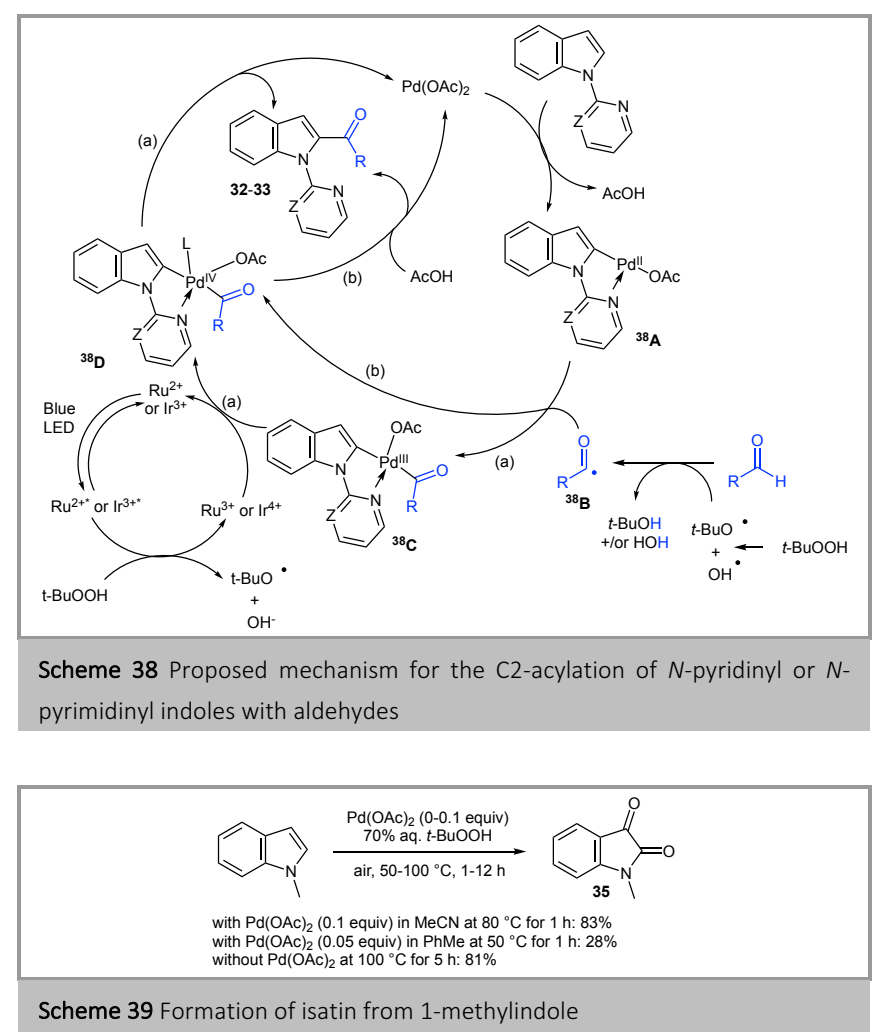

\subsection{Alcohols}

The C2-aroylation of $\mathrm{N}$-(pyrimidin-2-yl) indole with benzylic alcohols and $t$-BuOOH occurs either at $100{ }^{\circ} \mathrm{C}$ under $\mathrm{PdCl}_{2}$ catalysis $^{61}$ or at room temperature using the $\mathrm{Pd}(\mathrm{OAc})_{2}$ /photoredox procedure (Scheme 40). ${ }^{55,62}$ The benzylic alcohols would be oxidized into the corresponding aldehydes under the reaction conditions, hence a mechanism leading to the coupling products as depicted in Scheme 38 would operate. The alcohol oxidation with the $\mathrm{Pd}(\mathrm{OAc})_{2} / t-\mathrm{BuOOH}$ association was proposed, ${ }^{55}$ but a previous report assumed the $\mathrm{Pd}(\mathrm{OAc})_{2}$-free oxidation of benzyl alcohol with $t$-BuOOH. ${ }^{63}$

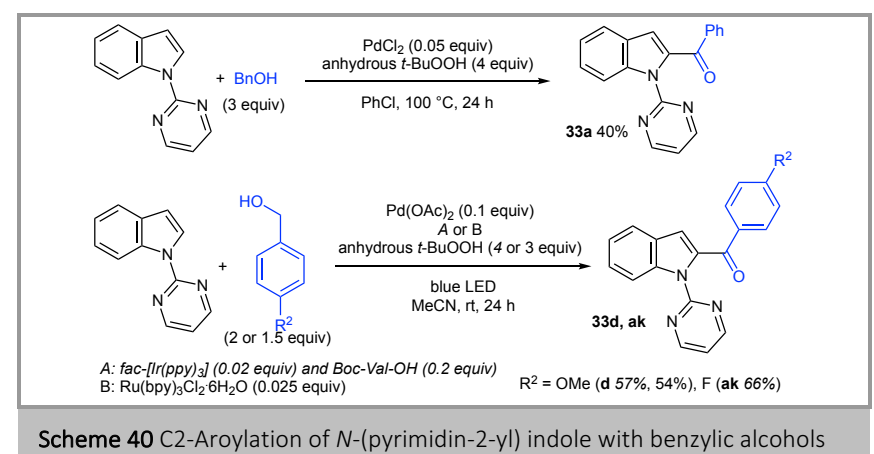

\section{3. $\alpha$-Diketones}

The $\mathrm{PdCl}_{2} / t$-BuOOH system led to the C2-acylation of $\mathrm{N}$ (pyrimidin-2-yl)indoles with a variety of $\alpha$-diketones (Scheme 41). Asymmetric $\alpha$-diketones provided a mixture of the two acylated coupling products 33 (Scheme 42).61 Homolytic cleavage of OC-CO bond of the diketone by $t$-BuOOH would lead to acyl radicals which, as above, would add to $\mathbf{X V}$ (see Scheme 38). In agreement with this proposal, only traces of the acylated indole were produced in the presence of $p$-benzoquinone as a radical scavenger (Scheme 41).
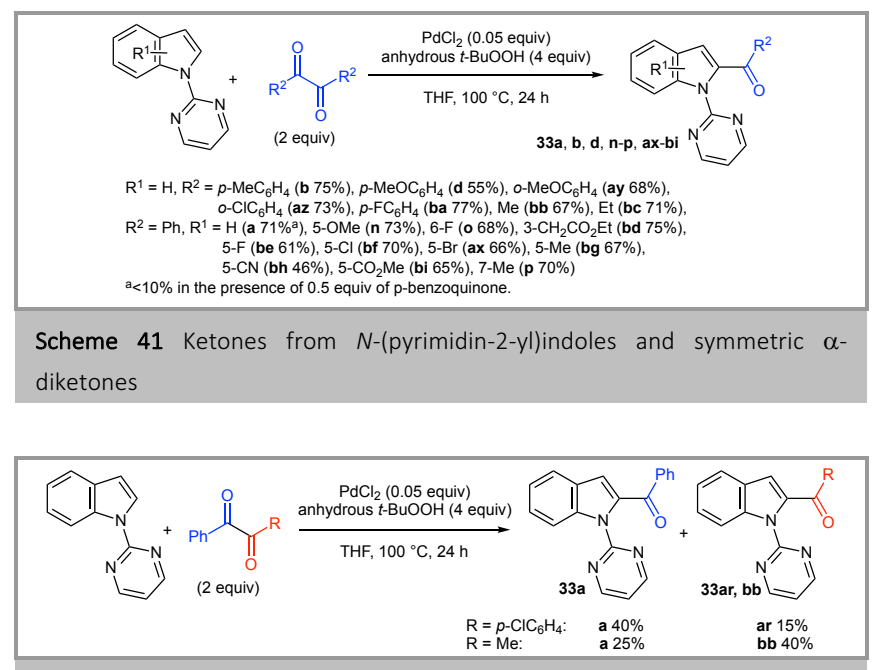

Scheme 42 Mixture of ketones from $N$-(pyrimidin-2-yl)indoles and asymmetric $\alpha$-diketones

\section{4. $\alpha$-0xo esters}

Use of $\mathrm{Pd}(\mathrm{OAc})_{2}$ catalysis and $t$-BuOOH at $125{ }^{\circ} \mathrm{C}$ in EtOAc allowed the coupling reaction of $N$-(pyrimidin-2-yl)indoles with ethyl glyoxylate to afford the corresponding ethyl 2-indole carboxylates 36a-i (Scheme 43). ${ }^{53}$ The $\mathrm{CO}_{2}$ Et radical ${ }^{44} \mathbf{A}$ in situ produced as depicted in Scheme 44 coordinates to a palladium chelate such as ${ }^{\mathbf{3 8}} \mathbf{A}$ (see Scheme 38 ) to afford a PdII or PdIV intermediate which evolves towards the product.

Scheme 43 Indolyl carboxylates from $\mathrm{N}$-(pyrimidin-2-yl)indoles and ethyl
glyoxylate

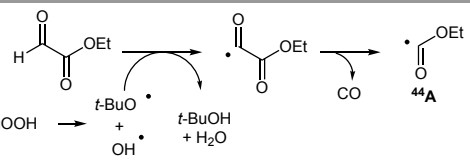

Scheme 44 Formation of the $\mathrm{CO}_{2} \mathrm{Et}$ radical

\section{5. $\alpha$-0xocarboxylic acids}

In the presence of a catalytic amount of $\mathrm{PdCl}_{2}$ and a stoichiometric quantity of $\mathrm{Ag}_{2} \mathrm{CO}_{3}, \mathrm{~N}$-methylindole reacted with benzoylformic acid to afford 3-benzoyl- $N$-methylindole 3a (Scheme 45). ${ }^{64}$ Changing for $\mathrm{Pd}(\mathrm{OAc})_{2}$ and $\mathrm{Cu}(\mathrm{OAc})_{2}$ increased 
the yield, but the best result was finally obtained using only the copper salt.

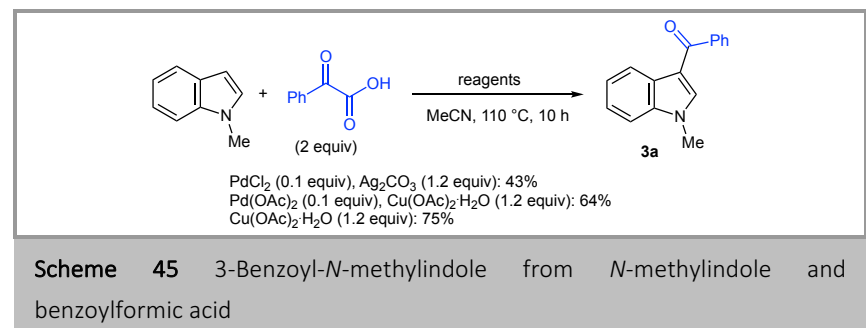

$\mathrm{Pd}(\mathrm{OAc})_{2}$ catalysis was nevertheless used to prepare a number of 2-(hetero)aroyl- $N$-(pyrimidin-2-yl)indoles $\mathbf{3 3}$ from the corresponding indoles and $\alpha$-oxocarboxylic acids in the presence of stoichiometric amounts of $\mathrm{Ag}_{2} \mathrm{O}$ and $\mathrm{K}_{2} \mathrm{~S}_{2} \mathrm{O}_{8}$, at 130 ${ }^{\circ} \mathrm{C}$ in a 1,4-dioxane/AcOH/DMSO mixture (Scheme 46). ${ }^{65}$ These syntheses could only involve the $\mathrm{Pd}^{\mathrm{II}} / \mathrm{Pd}^{0}$ redox catalytic cycle (Scheme 46). The anion exchange affords ${ }^{46} \mathbf{B}$ from palladacycle ${ }^{46} \mathrm{~A}$. Subsequent decarboxylation leads to ${ }^{46} \mathbf{C},{ }^{66}$ which suffers reductive elimination delivering the product and $\mathrm{Pd}^{0}$. The oxidative medium assumes the regeneration of $\mathrm{Pd}{ }^{\mathrm{II}}$ species. According to Zhu and co-workers, "the possibility of a PdII-PdIV mechanism could not be thoroughly ruled out". ${ }^{65}$

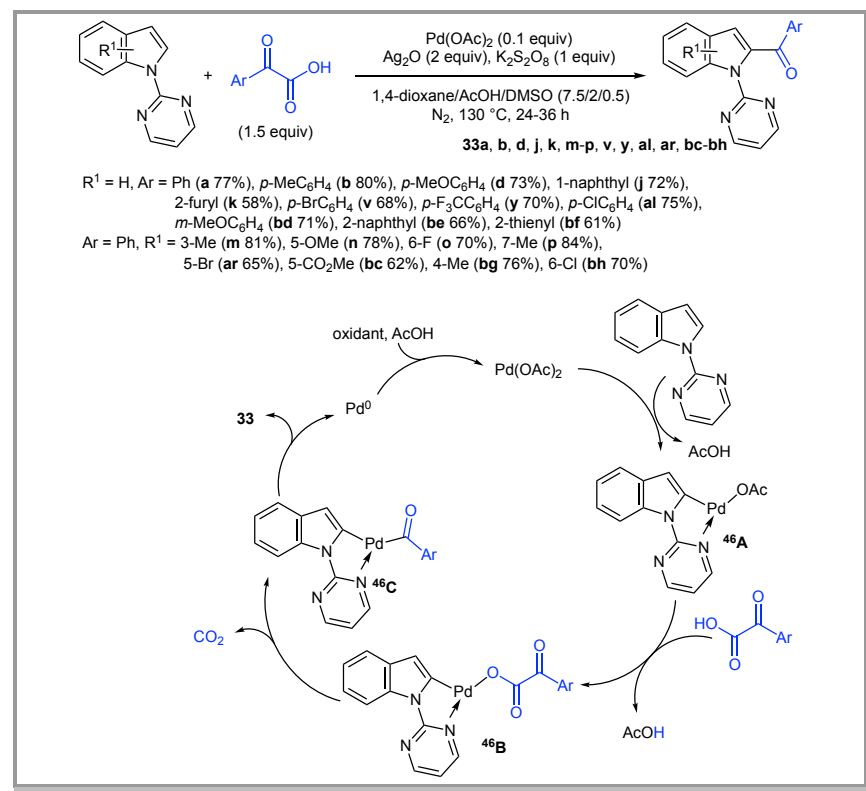

Scheme $46 \mathrm{C} 2$-(Hetero)aroylation of $N$-(pyrimidin-2-yl)indoles with $\alpha$ oxocarboxylic acids and proposed mechanism

The Jiang and Ji team recently disclosed an efficient domino reaction leading to indolo[1,2- $a$ ]quinazolines $\mathbf{3 7 a - y}$ via the palladium-catalyzed decarboxylative annulation of 2 - $(1 \mathrm{H}$-indol1-yl)anilines with 2-oxo-2-arylacetic acids (Scheme 47). ${ }^{67}$ The best results were obtained in diglyme with $\mathrm{Pd}(\mathrm{OAc})_{2}$ as the catalyst and $\left(\mathrm{NH}_{4}\right)_{2} \mathrm{~S}_{2} \mathrm{O}_{8}$ as the oxidant. The reaction also occurred in 1,4-dioxane, but failed in DMSO, DMF and toluene or using 2-oxohexanoic acid instead of an aroylformic acid. The amine group of the substrate directs the $\mathrm{C} 2$-aroylation, and then reacts with the carbonyl group to deliver water and the annulation product. The good yields of $\mathbf{3 7 a}$ also isolated in the presence of radical scavengers (Scheme 47) agree with the mechanism of the aroylation depicted in Scheme 46.

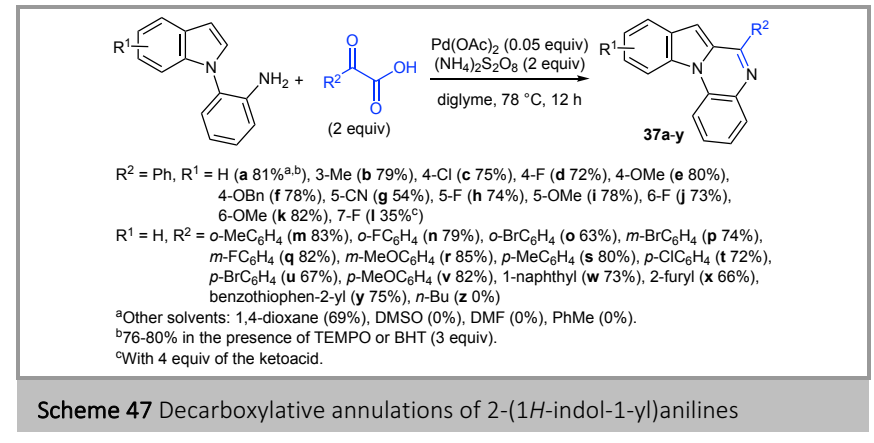

The Pd(OAc) $)_{2}$-catalyzed C3-acylation of $(\mathrm{NH})$-indoles with $\alpha$ oxocarboxylic acids was carried out using over-stoichiometric amounts of both $\mathrm{I}_{2}$ and $\mathrm{Cs}_{2} \mathrm{CO}_{3}$ at $45{ }^{\circ} \mathrm{C}$ in $\mathrm{N}$-methylpyrrolidone under oxygen (Scheme 48). ${ }^{68} \mathrm{Gu}$ and co-workers proposed the formation of 3-iodoindole as intermediate (see Section 2.2). Palladation of the latter would afford the iodopalladium complex. Subsequent exchange of $\mathrm{I}^{-}$for $\mathrm{R}^{2} \mathrm{COCO}_{2}$ - is followed by decarboxylation and reductive elimination to give the product. Thus, the proposed mechanism has strong similitudes with that of Scheme 46. Nevertheless, the authors attributed the oxidation state IV to the indolylpalladium intermediates.

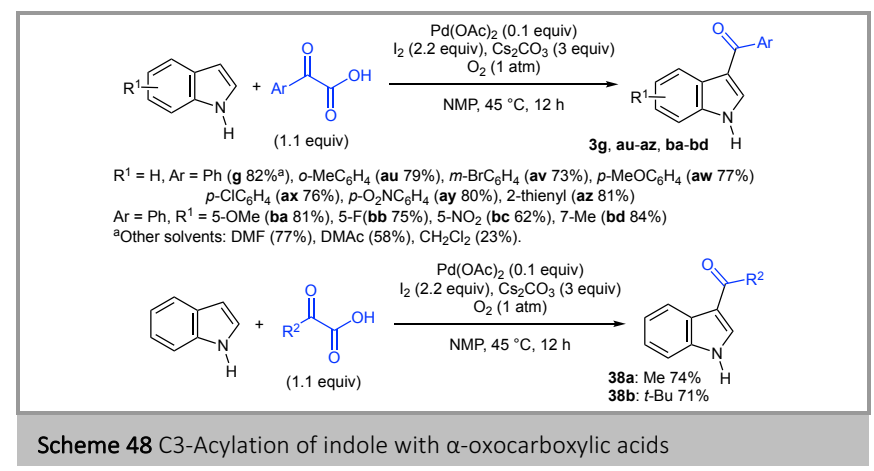

\subsection{Nitriles}

Under air atmosphere, indoles without directing $N$-substituent have been C3-acylated using nitriles and

- $\quad(1,10$-phenanthroline $) \operatorname{Pd}(\mathrm{OAc})_{2}$ as the catalyst, at 140 ${ }^{\circ} \mathrm{C}$ in 1,4-dioxane containing water and acetic acid (Scheme 49), ${ }^{69}$ 


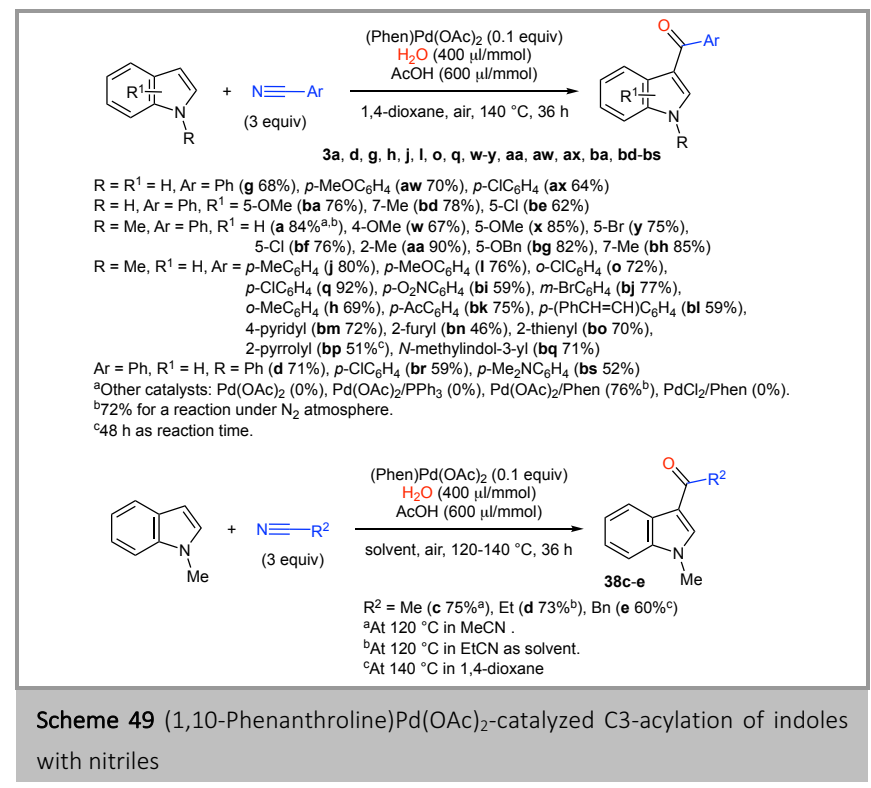

- $\quad \operatorname{Pd}(\mathrm{OAc})_{2} / 2,2^{\prime}$-bipyridine as the catalyst, at $120{ }^{\circ} \mathrm{C}$ in $\mathrm{N}$-methylacetamide containing camphorsulfonic acid and water (Scheme 50), ${ }^{70}$

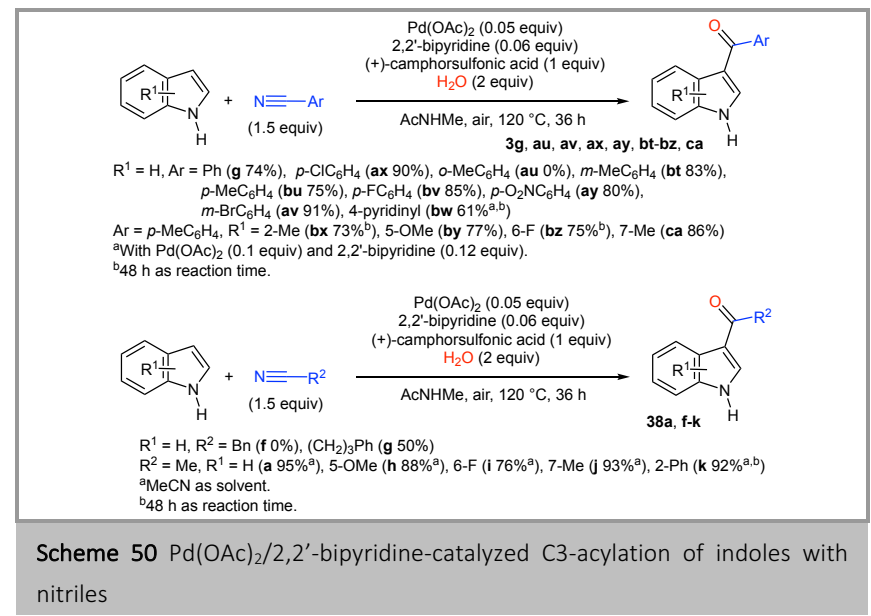

or

$\mathrm{Pd}(\mathrm{OAc})_{2} / 2$-(3,5-dimethylpyrazol-1-yl)pyridine as the catalyst, at $100{ }^{\circ} \mathrm{C}$ in a dioxane $/ \mathrm{AcOH} / \mathrm{H}_{2} \mathrm{O}$ mixture (Scheme 51). ${ }^{71}$

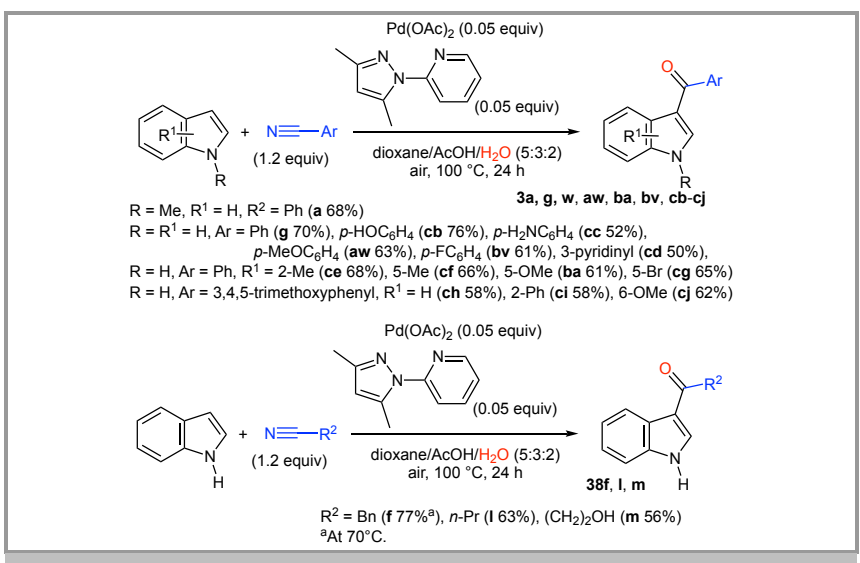

Scheme $51 \quad \mathrm{Pd}(\mathrm{OAC})_{2} / 2$-(3,5-dimethylpyrazol-1-yl)pyridine-catalyzed C3-

\section{acylation of indoles with nitriles}

The similar outcome of the reactions performed under air and nitrogen of the reaction with benzonitrile (Scheme 49) ${ }^{69}$ indicates that water provides the oxygen atom of the acylindole, hence the possible reaction mechanism depicted in Scheme 52. Palladation of the indole, followed by coordination of the nitrile leads to ${ }^{52} \mathbf{A}$. Carbopalladation of the $\mathrm{CN}$ unit gives the ketamine complex ${ }^{52} \mathbf{B}$, which, in the acid medium, evolves to ${ }^{52} \mathbf{C}$. Hydrolysis of the latter affords 3-acylindole 3. It was proposed that palladium intermediates are cationic species. ${ }^{70}$

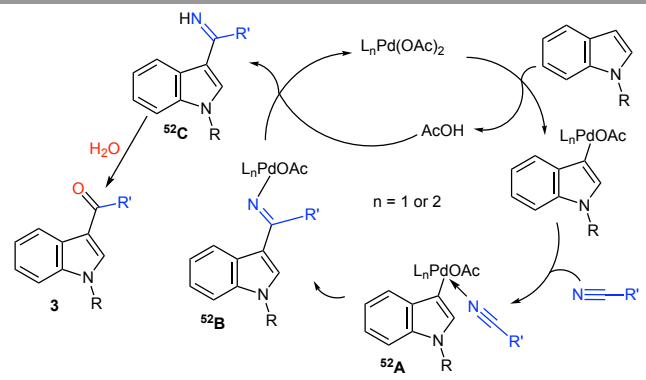

Scheme 52 Proposed mechanism for the acylation of indoles with nitriles

\subsection{Isocyanides}

The C3-carboamidation of indoles with isocyanides, reported by Zhu's team, using $\mathrm{Pd}(\mathrm{OAc})_{2}$ catalysis and air atmosphere, at 70 ${ }^{\circ} \mathrm{C}$ in THF containing copper acetate, trifluoroacetic acid and water, afforded secondary amides $15 \mathbf{v}, \mathbf{x}-\mathbf{z}$, aa-aw (Conditions A, Scheme 53). ${ }^{72}$ In the absence of trifluoroacetic acid and water (Conditions B), the reaction furnished tertiary $\mathrm{N}$-acetyl amides 40a-d as the main compounds (Scheme 53).

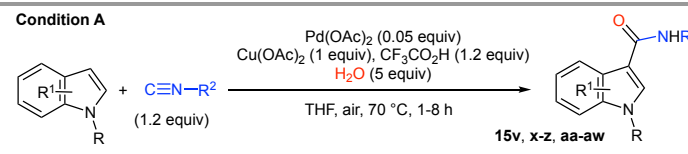

$\mathrm{R}=\mathrm{R}^{1}=\mathrm{H}, \mathrm{R}^{2}=t-\mathrm{Bu}(\mathbf{x} 92 \%), i-\operatorname{Pr}\left(\mathbf{y} 65 \%^{\mathrm{a}}\right), \mathrm{Cy}\left(\mathbf{z} 61 \%{ }^{\mathrm{a}}\right), 2,6-(\mathrm{Me})_{2} \mathrm{C}_{6} \mathrm{H}_{3}(\mathbf{a a} 58 \% \mathrm{~b})$,

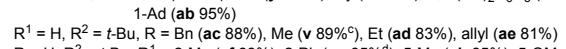

$\mathrm{R}=\mathrm{H}, \mathrm{R}^{2}=t-\mathrm{Bu}, \mathrm{R}^{1}=2-\mathrm{Me}($ af $88 \%), 2-\mathrm{Ph}\left(\right.$ ag $\left.65 \%{ }^{\mathrm{c}}\right), 5-\mathrm{Me}($ ah $85 \%), 5-\mathrm{OMe}($ ai $88 \%)$ 5- $\mathrm{OBn}$ (aj 86\%), 5- $\mathrm{OH}$ (ak 72\%), 5- $\mathrm{F}$ (al 94\%), 5-Cl (am 92\%),

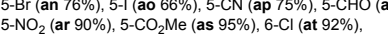
$5-\mathrm{NO}_{2}($ ar $90 \%), 5-\mathrm{CO}_{2} \mathrm{Me}($ as $95 \%), 6-\mathrm{Cl}($ at $92 \%)$
$6-\mathrm{Br}($ au $78 \%), 7-\mathrm{Me}($ av $96 \%), 7-\mathrm{Et}($ aw $94 \%)$ ${ }^{\mathrm{a}} \mathrm{Cu}\left(\mathrm{OCOCF}_{3}\right)_{2}$ instead of $\mathrm{Cu}(\mathrm{OAc})_{2}$.

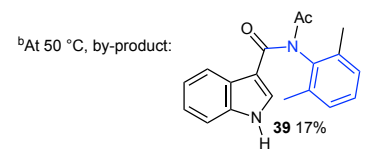

${ }^{c_{1}} 10 \%$ with $\mathrm{Pd}(\mathrm{OAc})_{2}\left(0.1\right.$ equiv) under $\mathrm{O}_{2}$ instead of $\mathrm{Cu}(\mathrm{OAc})_{2} /$ air. ${ }_{10 \%}$ with $\mathrm{Pd}(\mathrm{OAC})_{2}(0.1$ equiv) under
${ }^{\mathrm{dAt}} 50^{\circ} \mathrm{C}$ in $\mathrm{AcOH}$ without $\mathrm{CF}_{3} \mathrm{CO}_{2} \mathrm{H}$.

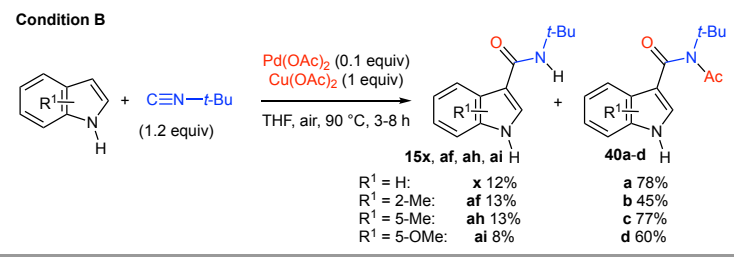

Scheme 53 C3-Carboamidation of indoles with isocyanides

Insights into the reaction were obtained using $\mathrm{H}_{2} \mathrm{O}^{18}$. With $\mathrm{CF}_{3} \mathrm{CO}_{2} \mathrm{H}$ as co-reagent, fully $\mathrm{O}^{18}$ was incorporated into the secondary amide 15x (Scheme 54). In contrast, without the acid, none of the oxygens of the tertiary $N$-acetyl amide 40 a was $0^{18}$ labeled, suggesting to the authors that both oxygen atoms "were 
derived from acetate" (Scheme 54). They also noted the absence of oxygen exchange between carbonyl oxygen of the secondary amide and $\mathrm{H}_{2} \mathrm{O}^{18}$. Given these observations, a plausible mechanism involves the PdII-mediated $\mathrm{C} 3-\mathrm{H}$ activation and the coordination of isocyanide to afford ${ }^{55} \mathbf{A}$ (Scheme 55). Insertion of $\mathrm{N} \equiv \mathrm{C}$ unit into the $\mathrm{C}-\mathrm{Pd}$ bond leads to ${ }^{55} \mathrm{~B}$. The presence of the acid favors quick ligand exchange of the acetate with water to yield ${ }^{55} \mathrm{C}$ (path $a$ ). From ${ }^{55} \mathrm{C}$, reductive elimination of $\mathrm{Pd}^{0}$ delivers 55D which furnishes the secondary amide $\mathbf{1 5}$ by tautomerization. Reductive elimination from ${ }^{55} \mathbf{B}$ is preferred in the absence of acid and water (path $b$ ). That results in the formation of the unstable imidic anhydride ${ }^{55} \mathbf{E}$. Tautomerization of the latter leads to the tertiary $\mathrm{N}$-acetyl amide $\mathbf{1 5}$. Regeneration of the active $\mathrm{Pd}^{\mathrm{II}}$ species is assumed by $\mathrm{Cu}(\mathrm{OAc})_{2}$.
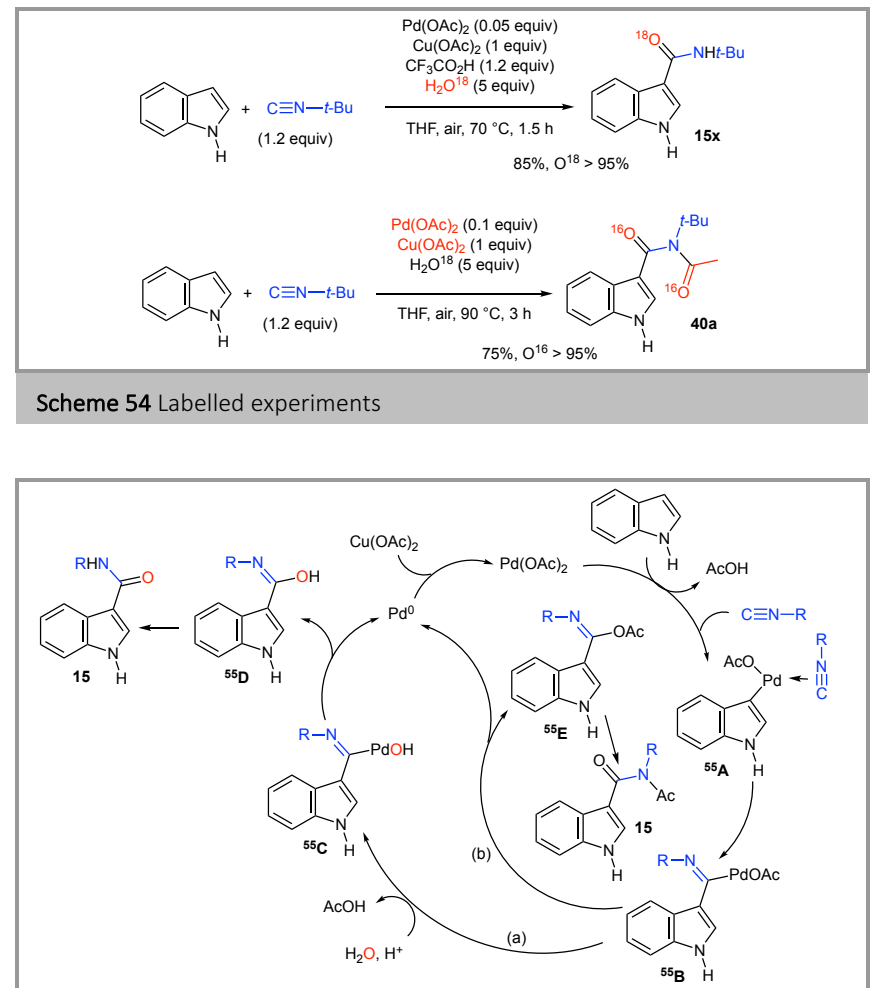

Scheme 55 Proposed mechanism for the carboamidation of indoles with isocyanides

Conditions A were effective for the C3-carboamidation of 2methylindole, 72 but led to only $10 \%$ yield of $\mathbf{1 5 a g}$ from 2 phenylindole 73 (Scheme 56). The use of AcOH as the solvent at $50{ }^{\circ} \mathrm{C}$ without $\mathrm{CF}_{3} \mathrm{CO}_{2} \mathrm{H}$ improved the yield to $65 \%$ and led to $5 \%$ of 2-phenyl-1 $H$-indole-3-carbonitrile $\mathbf{4 1}$ as side-product (Scheme 56). ${ }^{73}$ This intriguing cyanation has been studied in detail by Zhu and co-workers. ${ }^{73}$ Under Conditions A, 3methylindole underwent C2-carboamidation in a fair yield (Scheme 57). ${ }^{72}$

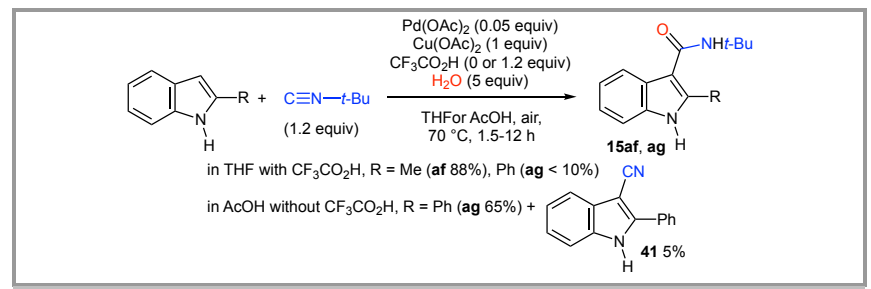

Scheme 56 C3-Carboamidation of 2-methylindoles with isocyanides

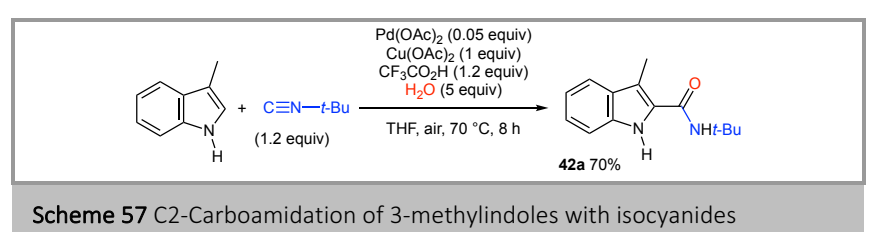

\subsection{Isothiocyanates and Isocyanates}

Recently, Swamy's team disclosed the PdII-catalyzed decarboxylative C2-amidation of indole-3-carboxylic acids with isothiocyanates. ${ }^{74}$ The most optimal conditions were attained with $\mathrm{Pd}(\mathrm{OAc})_{2}, \mathrm{Cs}_{2} \mathrm{CO}_{3}$ and $n-\mathrm{Bu} 4 \mathrm{NBr}$ in $\mathrm{MeCN}$ at $80{ }^{\circ} \mathrm{C}$ under air atmosphere (Scheme 58). C3-amidation arose from $\mathrm{N}$ methylindole-2-carboxylic acid (Scheme 59). Reaction of $\mathrm{N}$ methylindole-3-carboxylic acid with phenyl isocyanate instead of phenyl isothiocyanate gave a complex mixture containing only trace of the $\mathrm{C} 2$-amidation product. That could be due to the higher moisture sensitivity of the isocyanate. ${ }^{74}$

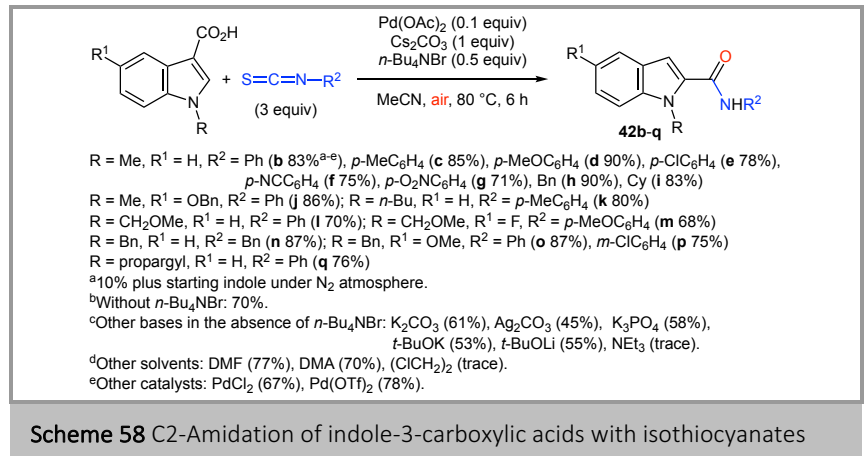

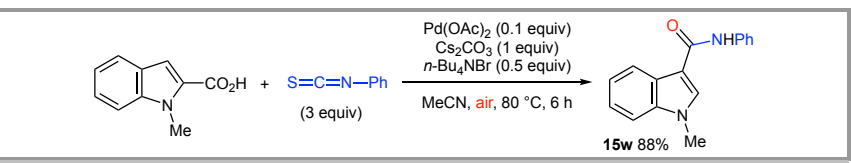

Scheme 59 C3-Amidation of $N$-methylindole-2-carboxylic acid with phenylisocyanate

The amidation of indole and $N$-methylindole did not occur under Swamy's conditions. The authors proposed the formation of the cesium indole-3-carboxylic carboxylate ${ }^{60} \mathbf{A}, \mathrm{C}\left(\mathrm{sp}^{2}\right)$ - $\mathrm{H}$ activation via $\eta^{2}$-coordination of the cesium carboxylate unit to $\mathrm{Pd}(\mathrm{OAc})_{2}$ leading to ${ }^{60} \mathbf{B}$, and a mechanism preserving the initial oxidation state of palladium all along the catalytic cycle (Scheme 60). ${ }^{74}$ Coordination of the isothiocyanate to ${ }^{60} \mathbf{B}$ followed by insertion of the $\mathrm{C}=\mathrm{N}$ double bond into the $\mathrm{Pd}-\mathrm{C}$ bond would result in the seven membered palladacycle ${ }^{60} \mathrm{C}$. Protonation at the amidic nitrogen of ${ }^{60} \mathrm{C}$ with $\mathrm{AcOH}$ would regenerate the catalyst and would afford ${ }^{60} \mathrm{D}$. Protodecarboxylation of the latter with in situ generated $\mathrm{CsHCO}_{3}$ would lead to indole-2-thioamide ${ }^{60} \mathbf{E}$ which would be oxidized with $\mathrm{O}_{2}$ into the corresponding amide $\mathbf{4 2}$. The 
authors noted that their failure to isolate the indole-2-thioamide would deserve further investigation. We are surprised by the no intervention of palladium indole carboxylate (that is an intermediate such as ${ }^{60} \mathbf{A}$ with $\mathrm{Pd}$ instead of $\mathrm{Cs}$ ) in the catalytic cycle, and also by the $\mathrm{CsHCO}_{3}$-mediated protodecarboxylation that efficiently affects ${ }^{60} \mathrm{D}$ but not ${ }^{60} \mathrm{~A}$. According to Scheme 60, only catalytic amounts of $\mathrm{Cs}_{2} \mathrm{CO}_{3}$ would be required. Moreover, we suspect a redox catalytic cycle, with air involved in the regeneration of active $\mathrm{Pd}^{\mathrm{II}}$ species. Indeed, performing the reaction under $\mathrm{N}_{2}$ instead of air produced $10 \%$ of the product, that is $100 \%$ yield calculated on the amount of $\mathrm{Pd}(\mathrm{OAc})_{2}$. Given the above remarks, the Swamy mechanism seems to be elusive. A catalytic cycle based on Lee's team proposal for the Pdcatalyzed decarboxylative C2-arylation of indole-3-carboxylic acids and C3-arylation of indole-2-carboxylic acids, which implies rearrangement of the palladium indole carboxylates, could be considered. 75

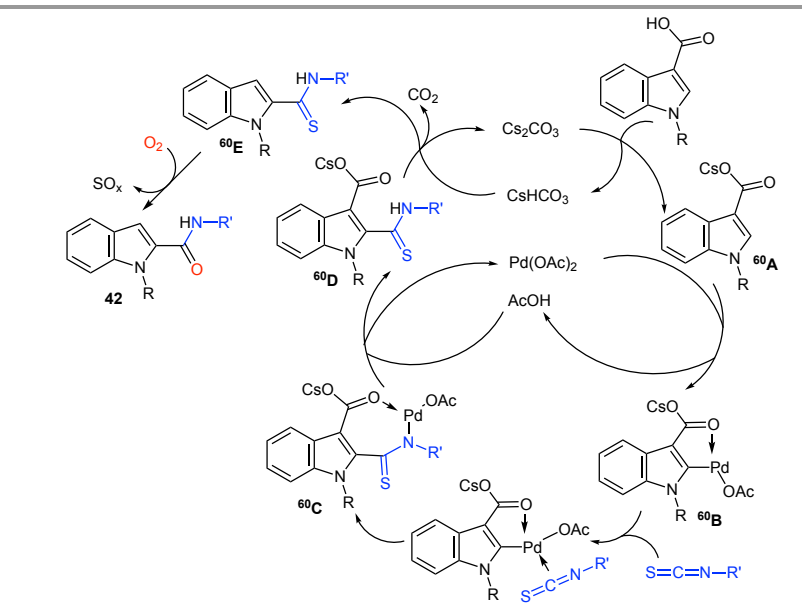

Scheme 60 Proposed mechanism for the C2-amidation of indole-3-carboxylic acids with isothiocyanates

\section{9. $\alpha$-Amino carbonyl compounds}

The reaction of indoles with $\alpha$-amino carbonyl compounds using the combination of $\mathrm{Pd}(\mathrm{OAc})_{2}$ catalyst, $\mathrm{Cu}(\mathrm{OAc})_{2}$ and air in $\mathrm{AcOH}$ led to indolyl diketones 43a-r (Scheme 61). ${ }^{76}$ The efficiency was highly dependent on the substitution of the amino group of the ketoamine (Scheme 62) and the nature of the co-reagents (Scheme 61). With 2-(methyl(phenyl)amino)-1phenylethanone, the coupling product 43a was isolated even in the absence of the Pd catalyst but with a low yield (Scheme 61). ${ }^{77}$ Reaction of 3-methylindole afforded the C2-substituted product 44b (Scheme 63).

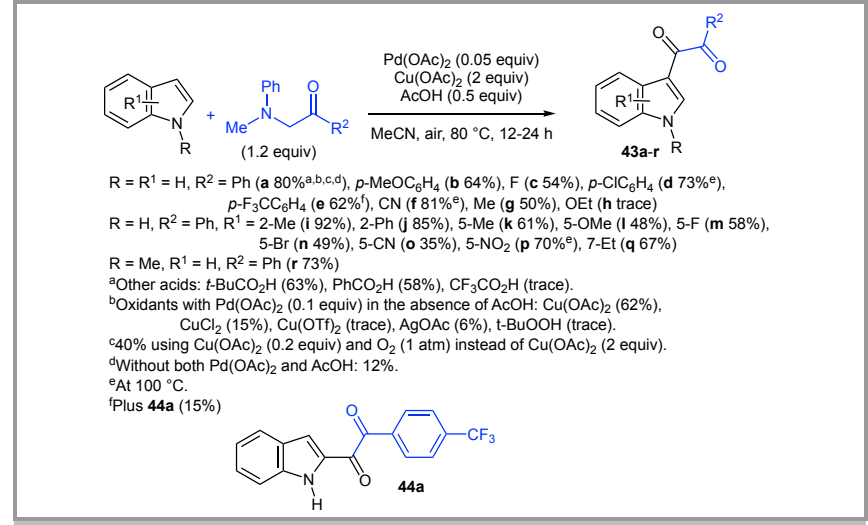

Scheme 61 C3-Indolyl diketones from indoles and $\alpha$-amino carbonyl compounds

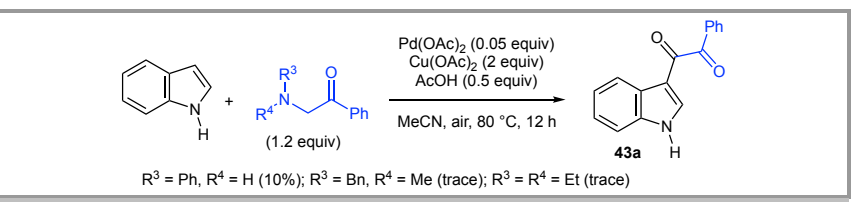

Scheme 62 C3-Indolyl diketones from indoles and various $N$-substituted $\alpha$ amino carbonyl compounds

Scheme $63 \mathrm{C}$-diketonisation of 3-methylindole

Performing the reaction in the presence of $\mathrm{H}_{2} \mathrm{O}^{18}$ showed the introduction of $\mathrm{O}^{18}$ into the indolyl diketone, indicating that the new oxygen atom was mainly from water. Without any indole substrate, the 2-(methyl(phenyl)amino)-1-phenylethanone was converted into the corresponding dicarbonyl compound but the latter did not react with indole under the optimal conditions. Thus, plausible reaction pathways leading to 1 - $(1 H$-indol-3-yl)2-phenylethane-1,2-dione are presented in Scheme 64. Palladium enolate ${ }^{64} \mathbf{A}$ formed from the $\alpha$-amino carbonyl compound and $\mathrm{Pd}(\mathrm{OAc})_{2}$ affords either iminium species ${ }^{64} \mathbf{B}$ via reductive elimination, or ${ }^{64} \mathrm{C}$ via $\mathrm{C}-\mathrm{H}$ activation of indole. Reductive elimination from ${ }^{64} \mathbf{C}$ would deliver ${ }^{64} \mathbf{D}$ which could also be obtained from ${ }^{64} \mathrm{~B}$ and indole. Pd ${ }^{\mathrm{II}}$-catalyzed oxidation of the $\mathrm{C}$ - $\mathrm{N}$ bond of ${ }^{64} \mathbf{D}$ affords ${ }^{64} \mathbf{E}$, hydrolysis of the latter giving indolyl diketone 43a. Interestingly, GC-MS monitoring of the oxidation of 2-(methyl(phenyl)amino)-1-phenylethanone detected ${ }^{64} \mathbf{B}$, while HRMS analysis of the coupling reaction determined ${ }^{64} \mathbf{E}$ as an intermediate. ${ }^{76}$ 


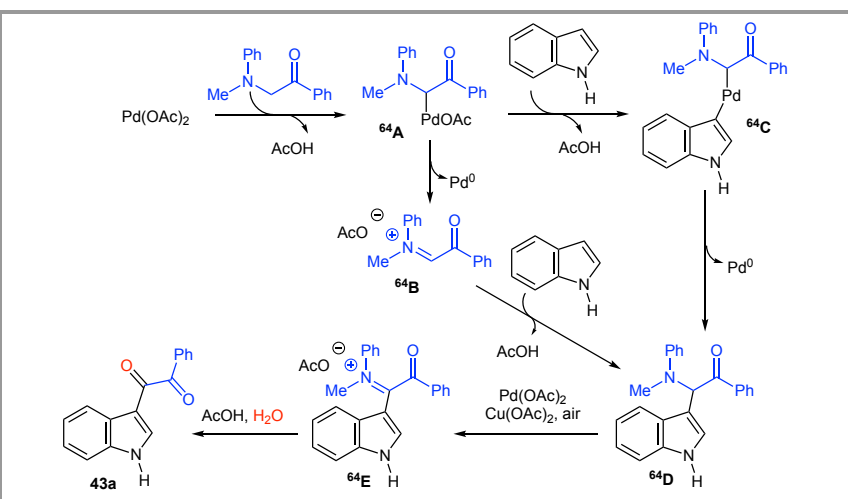

Scheme 64 Proposed mechanism for the reaction of indoles with $\alpha$-amino carbonyl compounds

\subsection{Vinyl ethers or vinyl amides}

The teams of Xue and Xiao reported the synthesis of 3acetylindoles $\mathbf{3 8 c}$, $\mathbf{n}-\mathbf{z}$, aa-ad from $N$-methyl- or $N$-benzylindoles and vinyl ethers or tertiary vinyl amides using $\mathrm{Pd}\left(\mathrm{OCOCF}_{3}\right)_{2}$ as catalyst, $\mathrm{Cu}(\mathrm{OAc})_{2}$ to regenerate the catalyst and $\mathrm{H}_{2} \mathrm{O}$ in a $1: 1$ mixture of DMF and DMSO. ${ }^{78}$ The yields depend on the solvent and the amount of water. The use of 3 equivalents of water was found to be the most optimal (Scheme 65). Increase or decrease of this ratio led to dropping of the yield up to $0 \%$ (Scheme 65).

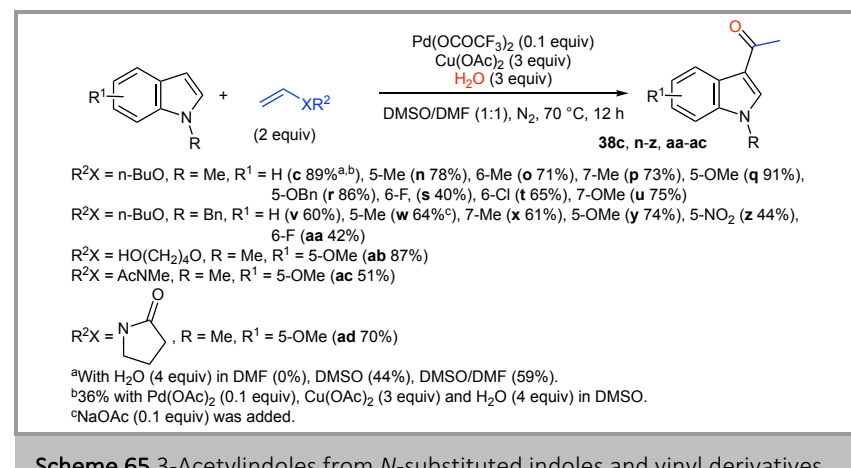

Scheme 65 3-Acetylindoles from $N$-substituted indoles and vinyl derivatives

The authors suspect that $\mathrm{H}_{2} \mathrm{O}$ promotes the dissociation of the anion from $\mathrm{Pd}\left(\mathrm{OCOCF}_{3}\right)_{2}$ leading to a cationic $\mathrm{Pd}{ }^{\mathrm{II}}$ which catalyzes the dehydrogenative Heck reaction between the indole and the electron-rich olefin. ${ }^{79}$ Coordination of the vinylic compound to the cationic catalyst would produce ${ }^{66} \mathrm{~A}$ (Scheme 66). That coordination was preferred because new resonances arose at room temperature in the ${ }^{1} \mathrm{H}$ NMR spectrum of a mixture of 1-(vinyloxy)butane and $\operatorname{Pd}\left(\mathrm{OCOCF}_{3}\right)_{2}$, while spectrum modification was not observed using $\mathrm{N}$-methylindole and $\mathrm{Pd}\left(\mathrm{OCOCF}_{3}\right)_{2}$. Reaction of the indole with ${ }^{\mathbf{6}} \mathbf{A}$ would afford ${ }^{66} \mathbf{B}$, which would suffer $\beta$-H elimination leading to ${ }^{66} \mathbf{C}$. Subsequent hydrolysis of ${ }^{66} \mathbf{C}$ gives 3 -acetylindole 38c. The catalytic cycle could nevertheless involve the reaction with indole rather than with the vinyl ether, because the 3 position of $N$-methylindole is deuterated by heating at $70{ }^{\circ} \mathrm{C}$ in the presence of $\mathrm{Pd}\left(\mathrm{OCOCF}_{3}\right)_{2}$ ( 0.1 equiv) and $\mathrm{D}_{2} \mathrm{O}$ ( 3 equiv).

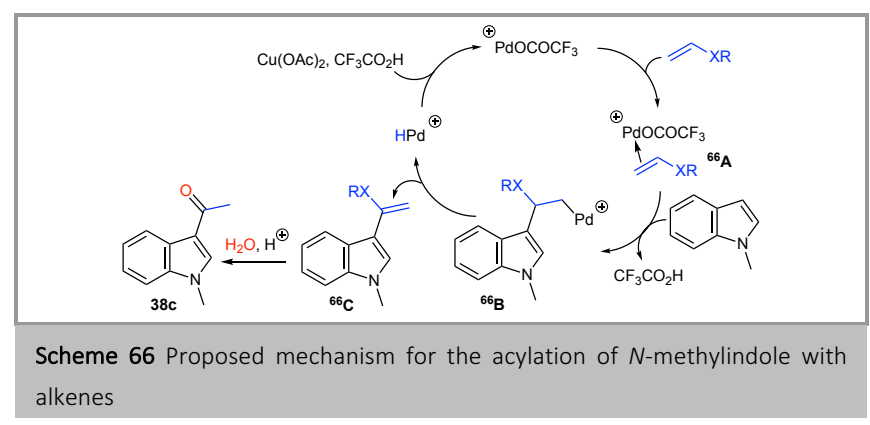

\subsection{Toluenes}

In 2015, Wu, Liu and co-workers who studied different agents for the C2-acylation of $\mathrm{N}$-(pyrimidin-2-yl)indole (Scheme 4042 ), obtained the benzoylation adduct 33a in $20 \%$ yield, using toluene with $\mathrm{Pd}(\mathrm{OAc})_{2}$ as catalyst and anhydrous $t$-BuOOH as the oxidant (Scheme 67). ${ }^{61}$

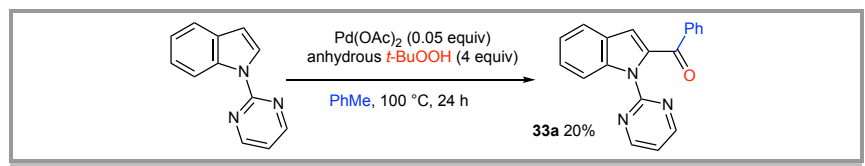

Scheme 67 C2-Benzoylation of $\mathrm{N}$-(pyrimidin-2-yl)indole with toluene

The efficiency greatly increased under conditions subsequently reported by Van der Eycken's team:80 $\mathrm{PdBr}_{2}$ as catalyst and pivalic acid as additive at $120{ }^{\circ} \mathrm{C}$ in a $\mathrm{PhMe} / \mathrm{PhCl}$ mixture (Scheme 68). ${ }^{81}$ Tested for the benzoylation of indoles variously $\mathrm{N}$-substituted, these conditions have been revealed also effective for the functionalization of $N$-(pyridin-2-yl) indole (Scheme 68). They were also efficient with toluene derivatives except those with an electron withdrawing group such as acetyl and nitro (Scheme 69).
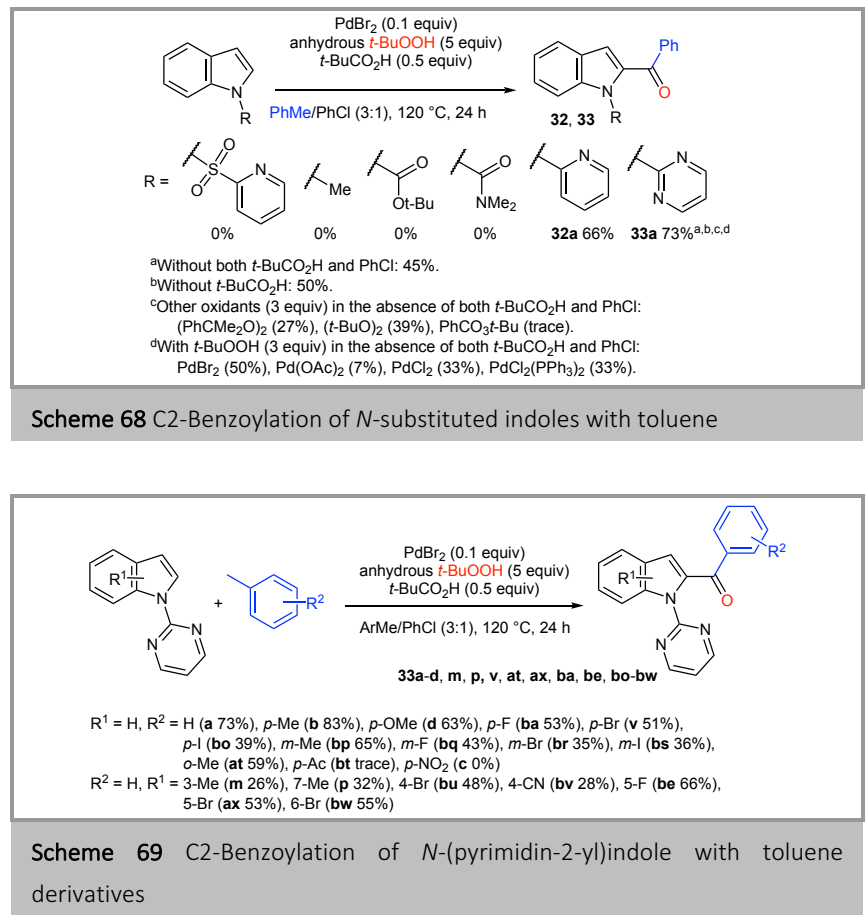

The above reactions involve the oxidation of ArMe into the corresponding aldehyde, a reaction with $t$ - $\mathrm{BuOOH}$ occurring even in the absence of any metal catalyst. ${ }^{82}$ Then, the 
benzoylation would proceed as above depicted in Scheme 39. Recently, a different reaction leading to isatin was reported by Luo's team using $\mathrm{Pd}(\mathrm{OAc})_{2}$ and aqueous $t$ - $\mathrm{BuOOH}$ in toluene (Scheme 39). 59

\subsection{Bromodichloromethane}

Recently, Wang's team disclosed the C2-formylation of 3substituted indoles via hydrolysis of the C2-methylene diacetates obtained from the Pd-catalyzed reaction with bromodichloromethane and acetic anhydride (Scheme 70). ${ }^{83}$ The homolytic cleavage of the $\mathrm{C}-\mathrm{Br}$ bond has been demonstrated, hence the $\mathrm{Pd}^{0} / \mathrm{Pd}^{\mathrm{II}}$ and unusual $\mathrm{Pd}^{0} / \mathrm{Pd}^{I}$ catalytic cycles proposed in Scheme 70. Addition of the dichloromethyl radical to the substrate leads to radical intermediate ${ }^{70} \mathrm{~A}$ which may evolve through two pathways:

reaction with $\mathrm{Pd}^{\mathrm{I}}$ complex providing the $\mathrm{Pd}^{\mathrm{II}}$

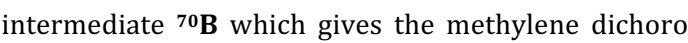
compound ${ }^{70} \mathrm{C}$ and the active catalytic species,

or

oxidation by $\mathrm{Pd}^{1}$ leading to $\mathrm{Pd}^{0}$ and ionic species ${ }^{70} \mathrm{D}$, reaction of the latter with base giving ${ }^{70} \mathbf{C}$.

The experimental conditions mediated the transformation of ${ }^{70} \mathrm{C}$ into acetal ${ }^{70} \mathbf{E}$ which was isolated, or hydrolyzed to afford the formylation product $\mathbf{1}$.

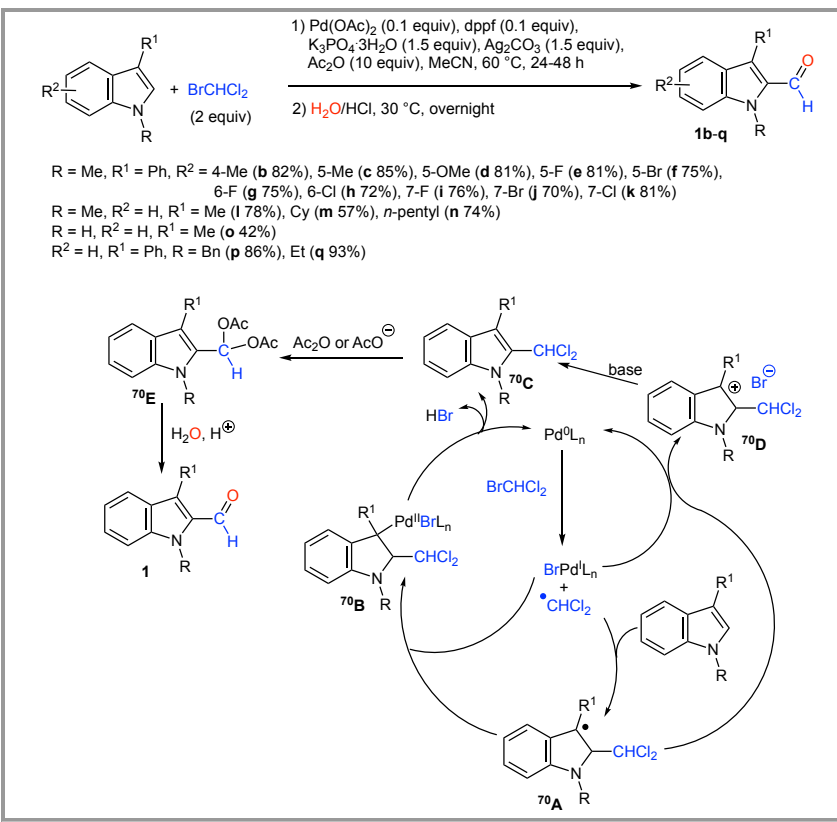

Scheme 70 C2-Formylation of 3 - and $\mathrm{N}$-substituted indoles with bromodichloromethane and proposed mechanism

\section{Conclusion}

The development of palladium catalytic systems for the substitution of the indole core with a carbonylated tether has grown considerably over the last years. The number of papers devoted to this rather restricted topic demonstrates that indole, more than 150 years after its discovery, ${ }^{84}$ remains the subject of intensive studies. Particularly interesting in the context of the green chemistry are the procedures avoiding preliminary functionalization. After $\mathrm{Pd}^{\mathrm{II}}$-mediated selective $\mathrm{C} 2-\mathrm{H}$ or $\mathrm{C} 3-\mathrm{H}$ activation of the indole, the acylation occurs via carbonylation, or using a variety of carbonylated or non carbonylated species, to afford coupling products open to further reactions.

\section{References}

(1) (a) Bandini, M.; Melloni, A.; Tommasi, S.; Umani-Ronchi, A. Synlett 2005, 1199-1222. (b) Joucla, L.; Djakovitch, L. Adv. Synth. Catal. 2009, 351, 673-714. (c) Bandini, M.; Eichholzer, A. Angew. Chem. Int. Ed. 2009, 48, 9608-9644. (e) Bartoli, G.; Bencivenni, G.: Dalpozzo, R. Chem. Soc. Rev. 2010, 39, 4449-4465. (d) Shiri, M. Chem. Rev. 2012, 112, 3508-3549. (e) Lancianesi, S.; Palmieri, A.; Petrini, M. Chem. Rev. 2014, 114, 7108-7149. (f) Dalpozzo, R. Chem. Soc. Rev. 2015, 44, 742-778. (g) Petrini, M. Chem. Eur. J. 2017, 23, 16115-16151. (h) Ziarani, G. M.; Moradi, R.; Ahmadi, T.; Lashgari, N. RSC Adv. 2018, 8, 12069-12103. (i) Pirovano, V. Eur. J. Org. Chem. 2018, 1925-1945. (j) Ieronimo, G.; Palmisano, G.; Maspero, A.; Marzorati, A.; Scapinello, L.; Masciocchi, N.; Cravotto, G.; Barge, A.; Simonetti, M.; Ameta, K. L.; Nicholas, K. M.; Penoni, A. Org. Biomol. Chem. 2018, 16, 6853-6859.

(2) (a) Norman, M. H.; Navas, F, III; Thompson, J. B.; Rigdon, G. C. J. Med. Chem. 1996, 39, 4692-4703. (b) Thurmond, R. L.; Desai, P. J.; Dunford, P. J.; Fung-Leung, W.-P.; Hofstra, C. L.; Jiang, W.; Nguyen, S.; Riley, J. P.; Sun, S.; Williams, K. N.; Edwards, J. P.; Karlsson, L. J. Pharmacol. Exp. Ther. 2004, 309, 404-413. (c) Pedras, M. S. C.; Yaya, E. E.; Glawischnig, E. Nat. Prod. Rep. 2011, 28, 1381-1405. (d) Sravanthi, T. V.; Manju, S. L. Eur. J. Pharm. Sci. 2016, 91, 1-10. (e) Chadha, N.; Silakari, O. Eur. J. Med. Chem. 2017, 134, 159-184. (f) Ciulla, M. G.; Kumar, K. Tetrahedron Lett. 2018, 59, 3223-3233.

(3) (a) Cacchi, S.; Fabrizi, G.; Chem. Rev. 2005, 105, 2873-2920. (b) Lang, R.; Xia, C.; Li, F. New J. Chem. 2014, 38, 2732-2738. (c) Wu, X.-F. Chem. Eur. J. 2015, 21, 12252-12265. (d) Yao, S.-J.; Ren, Z.-H.; Guan, Z.-H. Tetrahedron Lett. 2016, 57, 3892-3901. (e) Sharma, S.; Mishra, N. K.; Shin, Y.; Kim, I. S. Current Org. Chem. 2016, 20, 471511. (f) Wei, Y.; Hu, P.; Zhang, M.; Su, W. Chem. Rev. 2017, 117, 8864-8907. (g) Hummel, J. R.; Boerth, J. A.; Ellman, J. A. Chem. Rev. 2017, 117, 9163-9227. (h) Wegmann, M.; Henkel; M.; Bach, T. Org. Biomol. Chem. 2018, 16, 5376-5385. (i) Shah, T. A.; De, P. B.; Pradhan, S.; Punniyamurthy, T. Chem. Commun. 2019, 55, 572587.

(4) Grimster, N. P.; Gauntlett, C.; Godfrey, C. R. A.; Gaunt, M. J. Angew. Chem., Int. Ed. 2005, 44, 3185-3189.

(5) Stuart, D. R.; Villemure, E.; Fagnou, K. J. Am. Chem. Soc. 2007, 129, 12072-12073.

(6) Joucla, L.; Batail, N.; Djakovitch, L. Adv. Synth. Catal. 2010, 352, 2929-2936.

(7) Pi, J.-J.; Lu, X-Y.; Liu, J.-H.; Lu, X.; Xiao, B.; Fu, Y.; Guimond, N. J. Org. Chem. 2018, 83, 5791-5800.

(8) Moncea, O.; Poinsot, D.; Fokin, A. A.; Schreiner, P. R. ; Hierso, J.-C. ChemCatChem 2018, 10, 2915-2922.

(9) Potavathri, S.; Pereira, K. C.; Gorelsky, S. I.; Pike, A.; LeBris, A. P.; DeBoef, B. J. Am. Chem. Soc. 2010, 132, 14676-14681.

(10) Li, Y.; Wang, W.-H.; He, K.-H.; Shi, Z.-J. Organometallics 2012, 31, 4397-4400.

(11) Tokuyama, H.; Kaburagi, Y.; Chen, X.; Fukuyama, T. Synthesis 2000, 429-434.

(12) Zhao, M.-N.; Ran, L.; Chen, M.; Ren, Z.-H.; Wang, Y.-Y.; Guan, Z.-H. ACS Catal. 2015, 5, 1210-1213.

(13) Karpov, A. S.; Merkul, E.; Rominger, F.; Müller, T. J. J. Angew. Chem. Int. Ed. 2005, 44, 6951-6956.

(14) Herbert, J. M.; McNeill, A. H. Tetrahedron Lett. 1998, 39, 24212424.

(15) Buscemi, G.; Miller, P. W.; Kealey, S.; Gee, A. D.; Long, N. J.; Passchier, J.; Vilar, R. Org. Biomol. Chem. 2011, 9, 3499-3503.

(16) Kumar, K.; Zapf, A.; Michalik, D.; Tillack, A.; Heinrich, T.; Böttcher, H.; Arlt, M.; Beller, M. Org. Lett. 2004, 6, 7-10.

(17) Takács, A.; Marosvölgyi-Haskó, D.; Kabak-Solt, Z.; Damas, L.; Rodrigues, F. M. S.; Carrilho, R. M. B.; Pineiro, M.; Pereira, M. M.; Kollár, L. Tetrahedron 2016, 72, 247-256.

(18) Do, H.-Q.; Daugulis, O. J. Am. Chem. Soc. 2011, 133, 13577-13586. 
(19) Lang, R.; Shi, L.; Li, D.; Xia, C. G.; Li, F. W. Org. Lett. 2012, 14, 41304133.

(20) Li, D.; Shan, S.; Shi, L.; Lang, R.; Xia, C. G.; Li, F. W. Chin. J. Catal. 2013, 34, 185-192.

(21) Xing, Q.; Shi, L.; Lang, R.; Xia, C. G.; Li, F. W. Chem. Commun. 2012, 48, 11023-11025.

(22) Tu, D.; Luo, J.; Jiang, C. Chem. Commun. 2018, 54, 2514-2517.

(23) Ishikura, M.; Terashima, M. J. Org. Chem. 1994, 59, 2634-2637.

(24) Ishikura, M.; Imaizumi, K.; Katagiri, N. Heterocycles 2000, 53, 2201-2220.

(25) Ishikura, M.; Uchiyama, H.; Matsuzaki, N. Heterocycles 2001, 55, 1063-1070.

(26) Ishikura, M.; Matsuzaki, Y.; Agata, I. Chem. Commun. 1996, 24092410.

(27) Itahara, T. Chem. Lett. 1982, 1151-1152.

(28) Lang, R.; Wu, J.; Shi, L.; Xia, C.; Li, F. Chem. Commun. 2011, 47, 12553-1255.

(29) Zhang, H.; Liu, D.; Chen, C.; Liu, C.; Lei, A. Chem. Eur. J. 2011, 17, 9581-9585.

(30) (a) Larock, R. C.; Hightower, T. R. J. Org. Chem. 1993, 58, 52985300. (b) Muzart, J. In Comprehensive Organic Synthesis G. A. Molander, P. Knochel, Eds, 2nd Edition, Vol. 7, Oxford: Elsevier; 2014, pp 295-301.

(31) Tjutrins, J.; Arndtsen, B. A. J. Am. Chem. Soc. 2015, 137, 1205012054.

(32) Bis(indolyl)arylmethanes have been obtained using formic acid as CO source: Qi, X.; Ai, H.-J.; Zhang, N.; Peng, J.-B.; Ying, J.; Wu, X.-F. J. Catal. 2018, 362, 74-77.

(33) Nadres, E. T.; Lazareva, A.; Daugulis, O. J. Org. Chem. 2011, 76, 471-483.

(34) Liégault, B.; Petrov, I.; Gorelsky, S. I.; Fagnou, K. J. Org. Chem. 2010, 75, 1047-1060.

(35) Liu, J.; Wei, Z.; Jiao, H.; Jackstell, R.; Beller, M. ACS Cent. Sci. 2018, 4, 30-38.

(36) Ketcha, D. M.; Gribble, G. W. J. Org. Chem. 1985, 50, 5451-5457.

(37) Zeng, F.; Alper, H. Org. Lett. 2013, 15, 2034-2037.

(38) The positive charge of intermediate ${ }^{21} \mathbf{D}$ is missing in the original paper.

(39) For the formation of $\eta^{3}$-allyl palladium complexes from allyl alcohols and their reactivity, see: Muzart, J. Tetrahedron 2005, 61, 4179-4212.

(40) (a) Kimura, M; Futamata, M; Mukai, R.; Tamaru, Y. J. Am. Chem. Soc. 2005, 127, 4592-4593. (b) Tseng, Y.-L.; Liang, M-C.; Chen, I.C.; Wu, Y.-K. Synlett 2018, 29, 609-612.

(41) Wang, Z.; Yin, Z.; Wu, X.-F. Chem. Commun. 2018, 54, 4798-4801.

(42) Hegedus, L. S.; Sestrick, M. R.; Michaelson, E. T.; Harrington, P. J. J. Org. Chem. 1989, 54, 4141-4146.

(43) Harrington, P. J.; Hegedus, L. S. J. Org. Chem. 1984, 49, 2657-2662.

(44) Larock, R. C.; Bernhardt, J. C. J. Org. Chem. 1978, 43, 710-719.

(45) (a) Beak, P.; Lee, W. K. J. Org. Chem. 1993, 58, 1109-1117. (b) Hodson, F. M.; Madge, D. J.; Slawin, A. N. Z.; Widdowson, D. A.; Williams, D. J. Tetrahedron 1994, 50, 1899-1906.

(46) Labadie, S. S.; Teng, E. J. Org. Chem. 1994, 59, 4250-4254.

(47) Soley, R.; Albericio, F.; Álvarez, M. Synthesis 2007, 1559-1565.

(48) Labadie, J. W.; Stille, J. K. J. Am. Chem. Soc. 1983, 105, 6129-6137.

(49) Kianmehr, E.; Kazemi, S.; Foroumadi, A. Tetrahedron 2014, 70, 349-354.

(50) Yan, X.-B.; Shen, Y.-W.; Chen, D.-Q.; Gao, P.; Li, Y.-X.; Song, X.-R.; Liu, X.-Y.; Liang, Y.-M. Tetrahedron 2014, 70, 7490-7495.

(51) Li, D.; Wang, M.; Liu, J.; Zhao, Q.; Wang, L. Chem. Commun. 2013, 49, 3640-3642.

(52) Zhang, H.-J.; Wu, Z.; Lin, W.; Wen, T.-B. Chin. J. Chem. 2015, 33, 517-521.

(53) Wang, W.; Liu, J.; Gui, Q.; Tan, Z. Synlett 2015, 26, 771-778.
(54) Sharma, U. K.; Gemoets, H. P.; Schröder, F.; Noël, T.; Van der Eycken, E. V. ACS Catal. 2017, 7, 3818-3823.

(55) Manna, M. K.; Bairy, G.; Jana, R. Org. Biomol. Chem. 2017, 15, 58995903.

(56) Kumar, G.; Sekar, G. RSC Adv. 2015, 5, 28292-28298.

(57) Jiang, H.; Gao, S.; Xu, J.; Wu, X.; Lin, A.; Yao, H. Adv. Synth. Catal. 2016, 358, 188-194.

(58) Hu, Q.; Liu, X.; Huang, F.; Wang, F.; Li, Q.; Zhang, W. Catal. Commun 2018, 113, 27-31.

(59) Luo, J.; Gao, S.; Ma, Y.; Ge G. Synlett 2018, 29, 969-973.

(60) Kothandapani, J.; Reddy, S. M. K.; Thamotharan, S.; Kumar, S. M.; Byrappa, K.; Ganesan, S. S. Eur. J. Org. Chem. 2018, 2762-2767.

(61) Li, C.; Zhu, W.; Shu, S.; Wu, X.; Liu, H. Eur. J. Org. Chem. 2015, 37433750.

(62) Pd-catalyzed C3-alkylation of indoles with alcohols has been reported under non-oxidative conditions: Putra, A. E.; Takigawa, K.; Tanaka, H.; Ito, Y.; Oe, Y.; Ohta, T. Eur. J. Org. Chem. 2013, 28, 6344-6354.

(63) Park, J.; Kim, A.; Sharma, S.; Kim, M.; Park, E.; Jeon, Y.; Lee, Y.; Kwak, J. H.; Jung, Y. H.; Kim, I. S. Org. Biomol. Chem. 2013, 11, 2766-2771.

(64) Yu, L.; Li, P.; Wang, L. Chem. Commun. 2013, 49, 2368-2370.

(65) Pan, C.; Jin, H.; Liu, X.; Cheng, Y.; Zhu, C. Chem. Commun. 2013, 49, 2933-2935.

(66) The decarboxylation could be mediated by the $\mathrm{Ag}_{2} \mathrm{O} / \mathrm{K}_{2} \mathrm{~S}_{2} \mathrm{O}_{8}$ association: Mandal, S.; Bera, T.; Dubey, G.; Saha, J.; Laha, J. K. ACS Catal. 2018, 8, 5085-5144.

(67) Jiang, G.; Wang, S.; Zhang, J.; Yu, J.; Zhang,Z.; Jia, F. Adv. Synth. Catal. In press

(68) Gu, L.-J.; Liu, J.-Y.; Zhang, L.-Z.; Xiong, Y.; Wang, R. Chin. Chem. Lett. 2014, 25, 90-92.

(69) Ma, Y.; You, J.; Song, F. Chem. Eur. J. 2013, 19, 1189-1193.

(70) Jiang, T. S.; Wang, G. W. Org. Lett. 2013, 15, 788-791.

(71) Das, T.; Chakraborty, A.; Sarkar, A. Tetrahedron Lett. 2014, 55, 7198-7202.

(72) Peng, J.; Liu, L.; Hu, Z.; Huang, J.; Zhu, Q. Chem. Commun. 2012, 48, 3772-3774.

(73) Peng J., Zhao J., Hu Z, Liang D, Huang J, Zhu Q. Org Lett. 2012, 14, 4966-4969.

(74) Tulichala, R. N. P.; Shankar, M.; Swamy, K. C. K. J. Org. Chem. 2018, 83, 4375-4383.

(75) Nandi, D.; Jhou, Y.-M.; Lee, J.-Y.; Kuo, B.-C.; Liu, C.-Y.; Huang, P.-W.; Lee, H. M. J. Org. Chem. 2012, 77, 9384-9390.

(76) Tang, R. Y.; Guo, X. K.; Xiang, J. N.; Li, J. H. J. Org. Chem. 2013, 78, 11163-11171.

(77) For an efficient procedure under Cu-catalysis, see: Wu, J.-C.; Song, R.-J.; Wang, Z.-Q.; Huang, X.-C.; Xie, Y.-X.; Li, J.-H. Angew. Chem., Int. Ed. 2012, 51, 3453-3457.

(78) Li, Y.; Xue, D.; Lu, W.; Fan, X.; Wang, C.; Xiao, J. RSC Adv. 2013, 3, 11463-11466.

(79) For a review on dehydrogenative Heck reactions, see: Le Bras, J.; Muzart, J. Chem. Rev. 2011, 111, 1170-1214.

(80) Zhao, Y.; Sharma, U. K.; Schröder, F.; Sharma, N.; Song, G.; Van der Eycken, E. V. RSC Adv. 2017, 7, 32559-32563.

(81) Anhydrous $t$-BuOOH solution (5.5 M in decane over molecular sieves) was used, Personal communication from Dr U. K. Sharma, April, 19, 2018.

(82) Song, H.; Chen, D.; Pi, C.; Cui, X.; Wu, Y. J. Org. Chem. 2014, 79, 2955-2962.

(83) Bao, Y.; Wang, J.-Y.; Zhang, Y.-X.; Li, Y.; Wang, X.-S. Tetrahedron Lett. 2018, 59, 3147-3150.

(84) (a) Baeyer, A. Ann. Chem. Pharm. 1866, 140, 295-296. (b) Baeyer, A.; Emmerling, A. Ber. Dtsch. Chem. Ges. 1869, 2, 679-685.

\section{Biosketches}




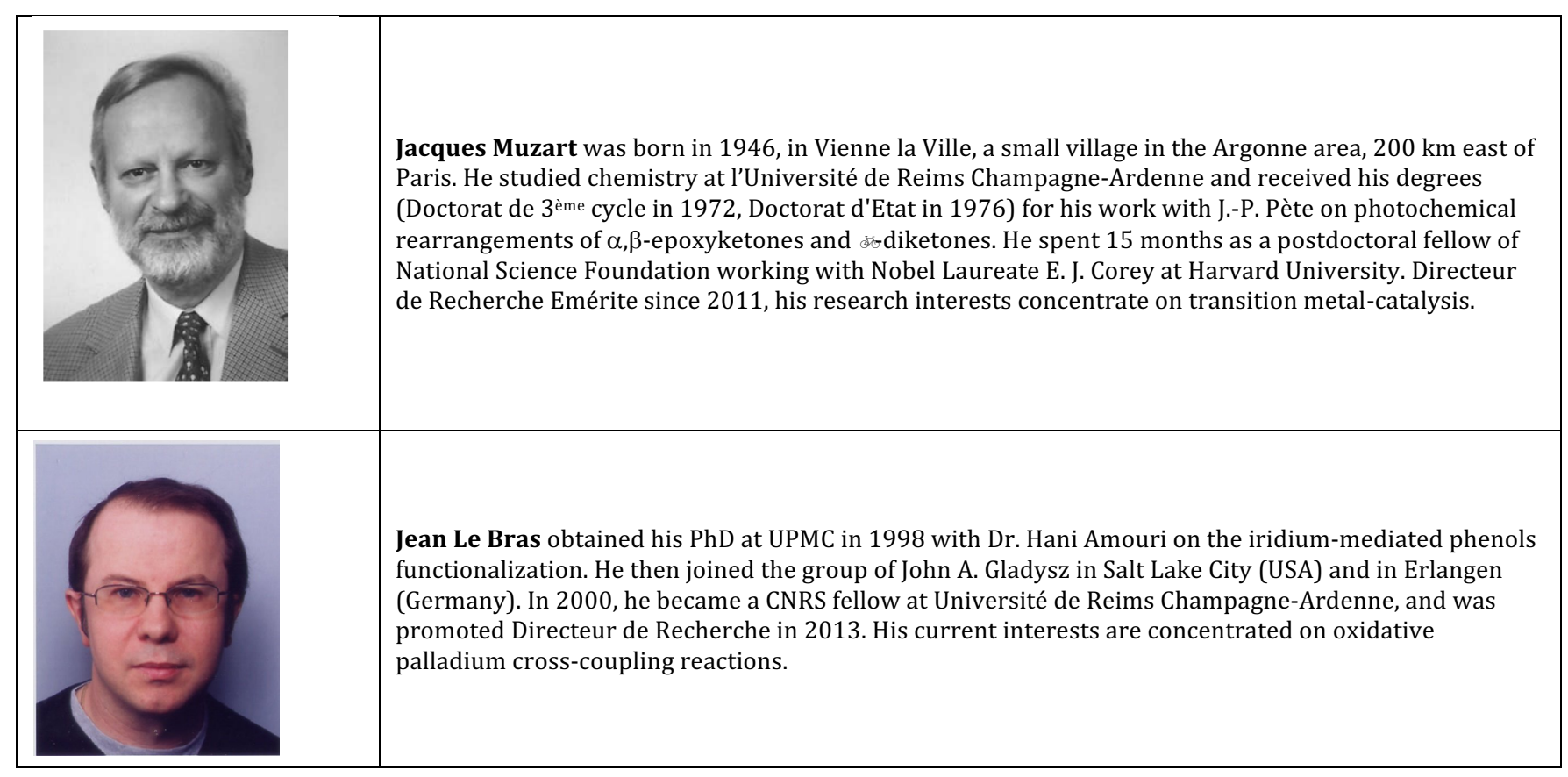

